\title{
Harnessing Resource Wealth for Inclusive Growth in Fragile States
}

Corinne Deléchat, Susan Yang, Will Clark, Pranav Gupta,

Malangu Kabedi-Mbuyi, Mesmin Koulet-Vickot, Carla Macario, Toomas Orav, Manuel Rosales, René Tapsoba and Dmitry Zhdankin 


\title{
IMF Working Paper
}

\author{
African and Research Departments
}

\section{Harnessing Natural Resources Wealth for Inclusive Growth in Fragile States}

\author{
Prepared by Corinne Deléchat, Susan Yang, Will Clark, Pranav Gupta, \\ Malangu Kabedi-Mbuyi, Mesmin Koulet-Vickot, Carla Macario, Toomas Orav, Manuel \\ Rosales, René Tapsoba and Dmitry Zhdankin ${ }^{1}$ \\ Authorized for distribution by Michel Lazare, Andrew Berg and Catherine Pattillo
} February 2015

This Working Paper should not be reported as representing the views of the IMF or DFID. The views expressed in this Working Paper are those of the author(s) and do not necessarily represent those of the IMF, IMF policy, or DFID. Working Papers describe research in progress by the author(s) and are published to elicit comments and to further debate.

\begin{abstract}
Like other fragile sub-Saharan African countries, Côte d'Ivoire, Guinea, Liberia, and Sierra Leone are seeking to harness their natural resource potential in the context of ambitious development strategies. This study investigates options for scaling up public investment and expanding social safety nets in a general equilibrium setting. First, it assesses the macro-fiscal implications of alternative fiscal rules for public investment, and, second, it explicitly accounts for redistribution through direct cash transfers. Results show that a sustainable non-resource deficit target is robust to the high uncertainty of resources output and prices, while delivering growth benefits through higher public investment. The scaling-up magnitudes, however, depend on the size of projected resource revenue and absorptive capacity. Adding a social transfer raises private consumption, suggesting that a fraction of the resource revenue could be used to expand safety nets.
\end{abstract}

JEL Classification Numbers: 011, 023, 041, 055, Q32

Keywords: Natural resources, West Africa, fragile states, social safety nets, inclusive growth

Authors’ E-Mail Addresses: cdelechat@imf.org, syang@imf.org, wclark2@imf.org, pgupta@imf.org, mkabedimbuyi@imf.org, mkouletvickot@imf.org, cmacario@imf.org, torav@imf.org, mrosales@imf.org, rtapsoba@imf.org, dzhdankin@imf.org.

\footnotetext{
${ }^{1}$ We are indebted to N. Le, A.A. Wane, A.O. Bah, and L.D. Mireaux for kind assistance with data collection, and to E. Fuli for her support with the FARI model. We also thank IMF seminar participants for insightful comments. This working paper is part of a research project on macroeconomic policy in low-income countries supported by U.K.'s Department for International Development (DFID).
} 


\section{Contents}

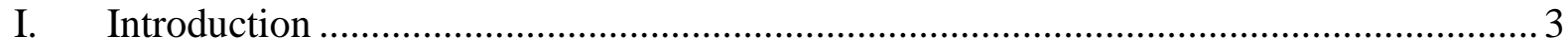

II. Key Development Challenges in the MRU Countries ............................................... 5

III. Natural Resource Revenue Projections ............................................................... 7

IV. Fiscal Frameworks for MRU Countries .......................................................... 11

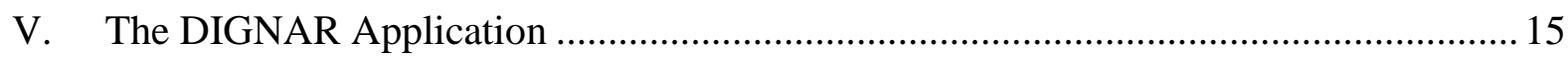

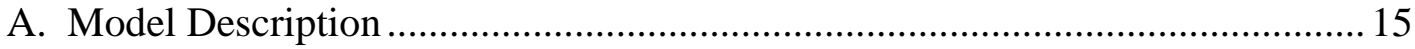

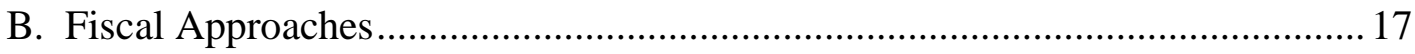

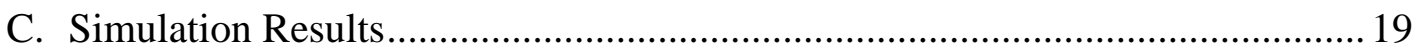

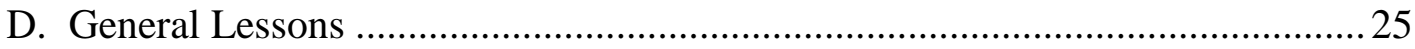

VI. Allocating Part of Resource Wealth to Social Protection ......................................... 26

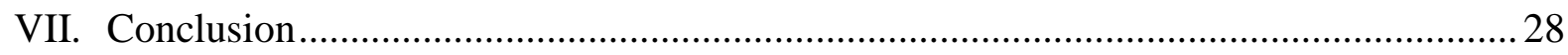

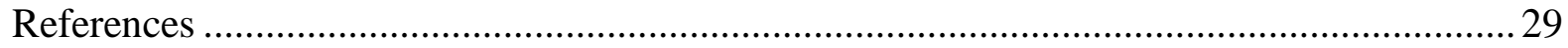

Boxes

1. Natural Resources Endowments in the MRU Countries ...................................... 8

2. Public Investment Efficiency in MRU Countries................................................. 18

3. The Recent Experience with Social Protection Systems ..................................... 27

Table

1. Resource-Rich Sub-Saharan African Fragile Countries......................................... 4

Figures

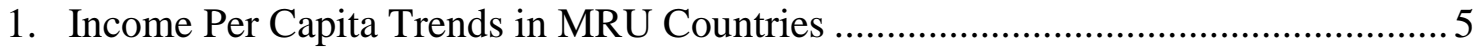

2. Social and Infrastructure Indicators in MRU Countries........................................ 6

3. Public Investment by Source of Financing, 2003-13 .......................................... 7

4. Current Natural Resource Revenue in MRU Countries ....................................... 8

5. The IMF's FARI Model .............................................................................. 9

6. Natural Resource Revenue Profiles Under Baseline and Optimistic Scenarios....... 11

7. Public Investment Paths Under Alternative Fiscal Rules...................................... 15

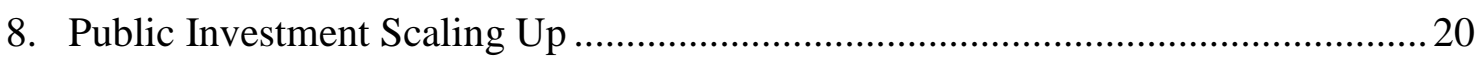

9. Macroeconomic Impact of Social Transfers .................................................. 21

10. Investment Efficiency in the Baseline and Optimistic Scenarios........................... 22

11. Adverse Iron-Ore Price Shock ......................................................................... 23

Appendixes

1. Poverty Diagnostics and Safety Nets in the MRU Countries ............................... 32

2. Fiscal Regimes and Resource Revenue Scenarios ............................................. 34

3. Model Specification, Solution Method, Calibration, and Simulation Results ......... 39 


\section{INTRODUCTION}

Fragile countries, many emerging from conflict, are faced with the urgent challenge of improving living conditions and providing employment opportunities for low skilled, idle youth. More than a welfare issue, this is critical to consolidate macroeconomic stability and maintain social cohesion as high poverty rates, inequality, and exclusion were often the root of the conflicts. As indicated in Table 1 below, 11 out of 19 sub-Saharan African countries in the World Bank's FY2015 Fragile Countries' list are endowed with abundant natural resources, though this potential remains mostly untapped. ${ }^{2}$ The confluence of latent resource wealth, renewed peace and political stability, and fiscal space from debt relief under multilateral debt relief initiatives (Highly Indebted Poor Countries/Multilateral Debt Relief Initiatives or HIPC/MDRI) provides these countries with a unique opportunity to close their large infrastructure gaps and improve social outcomes. However, fragile states face significant constraints in ensuring an efficient use of the additional resources: physical, human capital, and poverty gaps are larger and more pressing than in other countries, while administrative capacity is lower. ${ }^{3}$

This paper explores options to efficiently harness natural resource revenue to promote growth and reduce poverty, using a variant of the Debt, Investment, Growth and Natural Resources model (DIGNAR, see Melina et al., 2014). DIGNAR models were previously used to assess public investment scaling-up options in several countries, notably Chad, Mozambique, and Kazakhstan (IMF, 2014a, Melina and Xiong, 2013, and Minasyan and Yang, 2013). We add to this literature by assessing the macro-fiscal implications of alternative fiscal rules for public investment over the medium term and explicitly accounting for the possibility of redistribution through direct cash transfers. We apply the model to the four Mano River Union Countries (MRU) in West Africa, namely Côte d'Ivoire, Guinea, Liberia, and Sierra Leone. ${ }^{4}$ All four MRU countries have recently embarked on ambitious development strategies revolving around the exploitation of the resource wealth to scale up public investment, with a view to reaching middle-income country status during the next decade.

Several key policy messages come out of the four country cases. First and foremost, for countries like the ones studied where resource revenue is relatively small, fiscal space for scaling up public investment also needs to be generated by expanding of the non-revenue tax base and expenditure control, as well as improving investment efficiency. In these countries, a

\footnotetext{
${ }^{2}$ The list of Fragile Countries is available at http://siteresources.worldbank.org/EXTLICUS/Resources/5117771269623894864/FY15FragileSituationList.pdf. Recent reports by the Africa Progress Panel (2014) and the African Development Bank (AfDB, 2014) address how to harness the continent's natural resource wealth for all, with the AfDB report focusing on fragile countries.

${ }^{3}$ While these issues and constraints are more salient in the case of fragile countries, all resource-rich low-income countries face similar challenges and, in that sense, the main conclusions of this paper apply more broadly.

${ }^{4}$ The MRU serves as a cooperation forum on security and other cross-border topics. All four countries are also ECOWAS members.
} 
cautious investment scaling up strategy is recommended, as access to international capital markets is limited or nil and fiscal adjustment can be politically difficult.

\begin{tabular}{|c|c|c|c|c|c|c|c|}
\hline \multicolumn{8}{|c|}{ Table 1. Resource-Rich Sub-Saharan African Fragile Countries } \\
\hline Country & Natural resources & $\begin{array}{c}\text { Real GDP } \\
\text { per Capita } \\
\text { (constant } \\
2005 \text { US\$, } \\
2013 \text { ) }\end{array}$ & $\begin{array}{c}\text { Public } \\
\text { Debt to } \\
\text { GDP ratio } \\
\text { (2013) }\end{array}$ & $\begin{array}{c}\text { Natural } \\
\text { resource } \\
\text { revenue } \\
\text { (share of } \\
\text { total, } \\
2013 \text { ) } \\
\end{array}$ & $\begin{array}{c}\text { Poverty } \\
\text { headcount* }\end{array}$ & $\begin{array}{c}\text { Infant mortality } \\
\text { rate ( } 0-1 \text { year) } \\
\text { per } 1,000 \text { live } \\
\text { births** }\end{array}$ & $\begin{array}{c}\text { Paved Roads } \\
\text { (percent of } \\
\text { total roads)* }\end{array}$ \\
\hline Central African Republic & Diamonds; Gold & 282.6 & 50.9 & 8.4 & 62.8 & 90.7 & 3 \\
\hline Chad & Oil & 741.6 & 31.0 & 63.2 & 61.9 & 89.4 & 1 \\
\hline Cote d'Ivoire & Oil; Gas; Minerals & 1014.4 & 39.9 & 4.8 & 23.8 & 76.2 & 8 \\
\hline Democratic Rep. of Congo & Minerals/Oil & 288.2 & 20.0 & 28.5 & 87.7 & 99.9 & 2 \\
\hline Guinea & $\begin{array}{l}\text { Iron ore; Bauxite; } \\
\text { Gold; Diamonds }\end{array}$ & 308.0 & 39.5 & 18.7 & 43.3 & 65.2 & 10 \\
\hline Liberia & Iron Ore; Gold; Oil & 299.4 & 29.8 & 16.9 & 83.8 & 56.0 & 6 \\
\hline Madagascar & Oil & 265.2 & 34.2 & $\ldots$ & 81.3 & 40.9 & 12 \\
\hline Mali & Gold & 476.2 & 32.1 & 17.0 & 50.4 & 79.6 & 19 \\
\hline Sierra Leone & Iron ore; Diamonds & 513.2 & 30.5 & 14.2 & 51.7 & 117.4 & 8 \\
\hline South Sudan & Oil & 984.0 & 14.6 & 94.6 & $\ldots$ & 66.7 & $\ldots$ \\
\hline Togo & Phosphate & 424.4 & 44.6 & $\ldots$ & 28.2 & 62.0 & 21 \\
\hline $\begin{array}{l}\text { Sources: UNDP, World Bank Devel } \\
\text { * Refers to different years, depend } \\
\text { ** Refers to } 2012 \text {. }\end{array}$ & $\begin{array}{l}\text { ators, IMF staff Calculations. } \\
\text { vailability. }\end{array}$ & & & & & & \\
\hline
\end{tabular}

Second, sound fiscal regimes ensuring that governments get their fair share of resource revenue are essential. A regime that combines a royalty, corporate income tax and resource rent tax is essential for maximizing government revenue over project life, together with effective and transparent resource administration (IMF, 2012b).

Third, a simple fiscal rule based on a sustainable non-resource deficit is appropriate when natural resource revenue is relatively small as a share of total revenue. The rule can deliver a gradual scaling up of investment financed by a combination of resource revenue and sustainable borrowing, while remaining fairly robust to high resource revenue uncertainty. In contrast, a fiscal rule based on the permanent income hypothesis translates into a very conservative investment path.

Fourth, in the general equilibrium model, using some of the resource revenue to fund a social transfer raises private consumption and welfare, suggesting that, given limited amounts of total resource revenue, a small fraction of this revenue could be used to sustainably expand social safety nets and reduce poverty. Providing immediate and tangible benefits to the poorest and most vulnerable would help maintain social cohesion and create a broad constituency for transparency in natural resources management. 
The rest of the paper is structured as follows. Section II briefly presents the key development challenges for the region. Section III discusses medium-term resource revenue profiles and derives public investment paths under alternative fiscal rules. Section IV introduces and applies the DIGNAR model to the four countries. Section V discusses types of social safety nets and transfers that could be effective in the four countries, and Section VI concludes.

\section{Key DeVelopment Challenges In THE MRU COUNTRIES}

Two decades of civil conflicts and political crisis have taken a large toll on social and economic indicators in the MRU countries. Liberia and Sierra Leone experienced a decade of civil wars, while Côte d'Ivoire and Guinea faced protracted socio-political crises punctuated by short episodes of high tensions. As a result, Liberia and Sierra Leone were more severely affected than Côte d'Ivoire and Guinea (Figure 1). Nevertheless, MRU countries face similar development challenges, including high poverty and inequality, acute unemployment and social cohesion challenges associated with a "youth bulge", and large infrastructure gaps. Arguably, the lack of inclusiveness, together with competition for natural resources and existing ethnic and political tensions were at the source of the coups and civil conflicts.

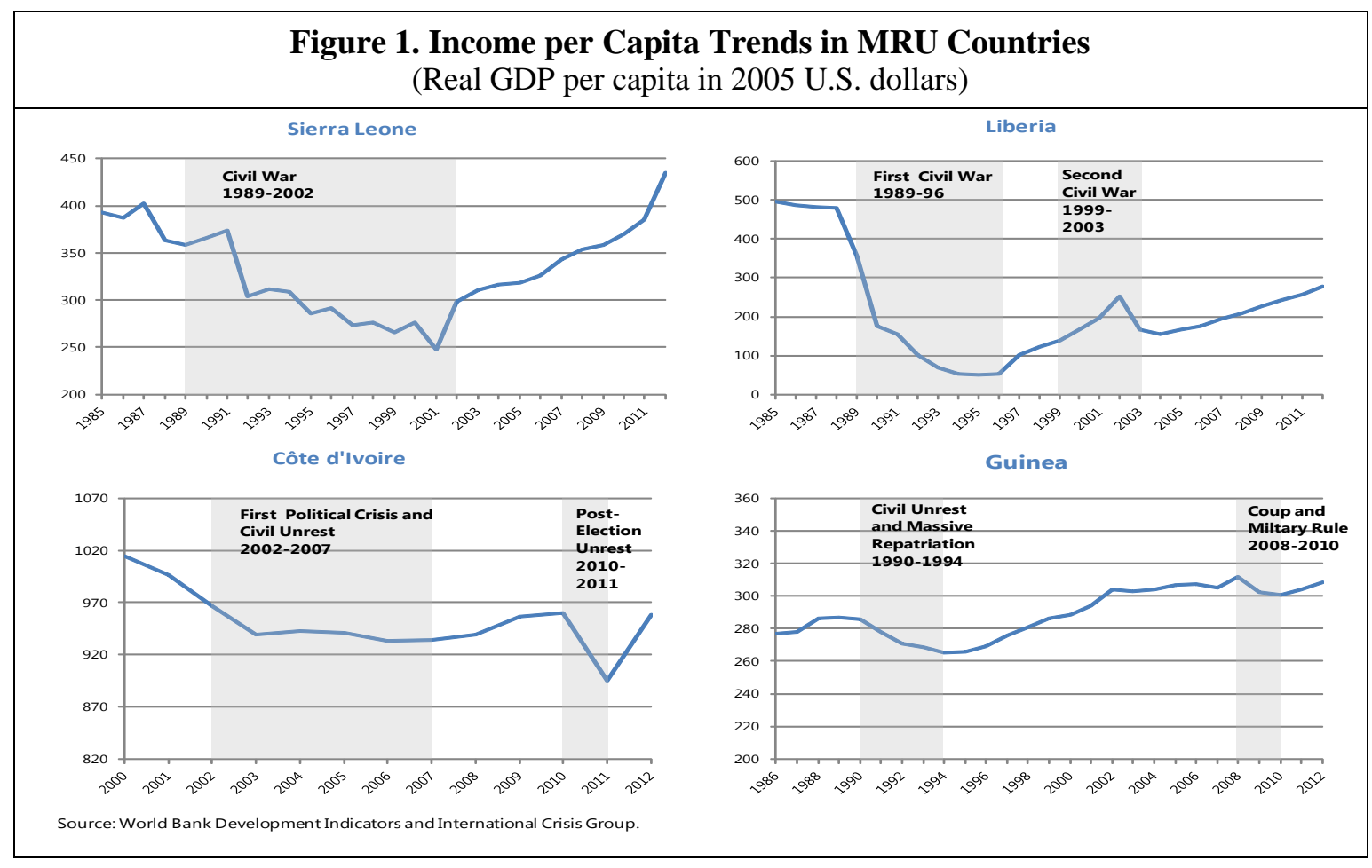

More than half of the population in MRU countries lives in poverty, and progress in reducing poverty has been mixed. Over the last decade, improved stability has enabled both Liberia and Sierra Leone to reduce poverty headcounts and improve social indicators. At the same time, Guinea and Côte d'Ivoire saw poverty headcounts rise and multi-dimensional indicators improved only modestly, owing to instability and lackluster growth. Despite recent gains, MRU countries generally lag behind peers on many social indicators (Figure 2). 
Poverty diagnostics indicate that poverty continues to be most severe in rural areas. Households led by women and elderly persons are typically the most vulnerable to poverty. Food insecurity is pervasive in Guinea, Liberia and Sierra Leone. Social safety nets are embryonic, mostly donor-funded and fragmented, and reach only a fraction of the poorest and most vulnerable groups. In all four MRU countries safety nets mostly focus on providing either direct food distributions (mostly school feedings) or temporary income support during the lean season in the form of public works program (Appendix 1).

As a result of the conflicts, the MRU countries face a serious basic infrastructure deficit, which weighs on growth and private sector development prospects. Transportation and energy bottlenecks appear more severe than in other fragile and LICs peers, have been identified as binding constraints on growth and private sector investment, and are justifiably a focus of their national development plans. ${ }^{5}$ Human capital also lags behind peer countries, as protracted civil conflicts have severely disrupted both health and education systems (Figure 2).

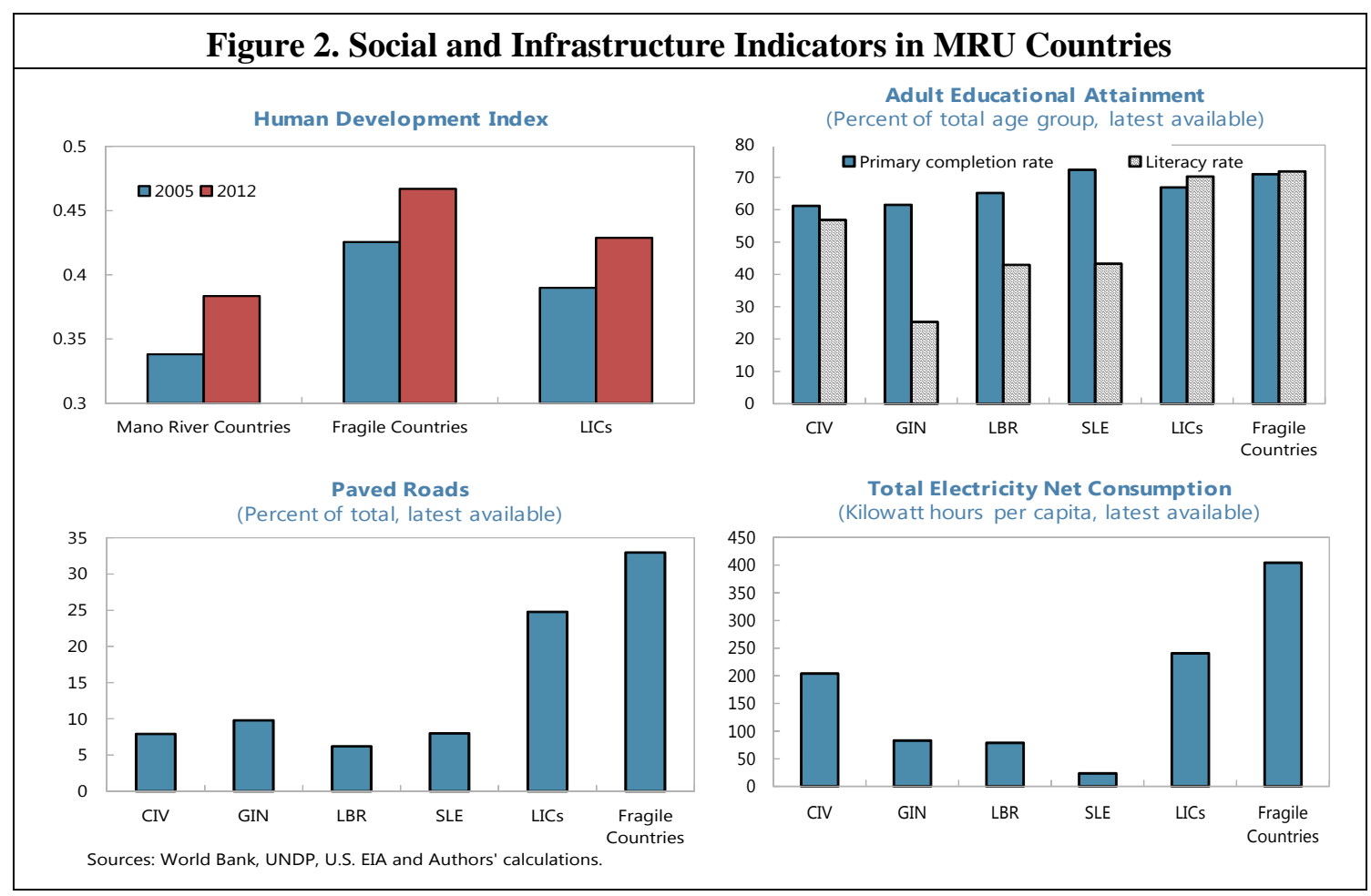

In turn, addressing these growth constraints is critical to provide meaningful opportunities to a rapidly-growing labor force and maintain social cohesion. With the labor force growing at about 3 percent per year, it is projected that by 2020 more than 7 million new jobs would have to be created in the four countries. Most of these jobs would have to be concentrated in

\footnotetext{
${ }^{5}$ See the poverty reduction strategy paper (PRSP) for Côte d'Ivoire and Guinea, and growth constraints diagnosis documents (building on the methodology developed by Hausman, Rodrick and Velasco, 2005), initiated for qualification to the US Millennium Challenge Corporation's grants, for Liberia and Sierra Leone.
} 
agriculture and services, as mining and oil extraction operations are highly capital intensive and manufacturing sectors are very small (Fox et al., 2014).

All four countries have elaborated multi-year strategies to tackle these development challenges. The poverty reduction strategies (PRS) explicitly target reaching middle income country status within a timeframe of 10 to 25 years, by scaling up public investment, particularly in infrastructure, to address the binding impediments to growth, and promoting inclusive growth by developing social safety nets to protect vulnerable groups. However, in recent years, the domestically-financed investments have remained limited, chiefly in Sierra Leone and Côte d'Ivoire (Figure 3).

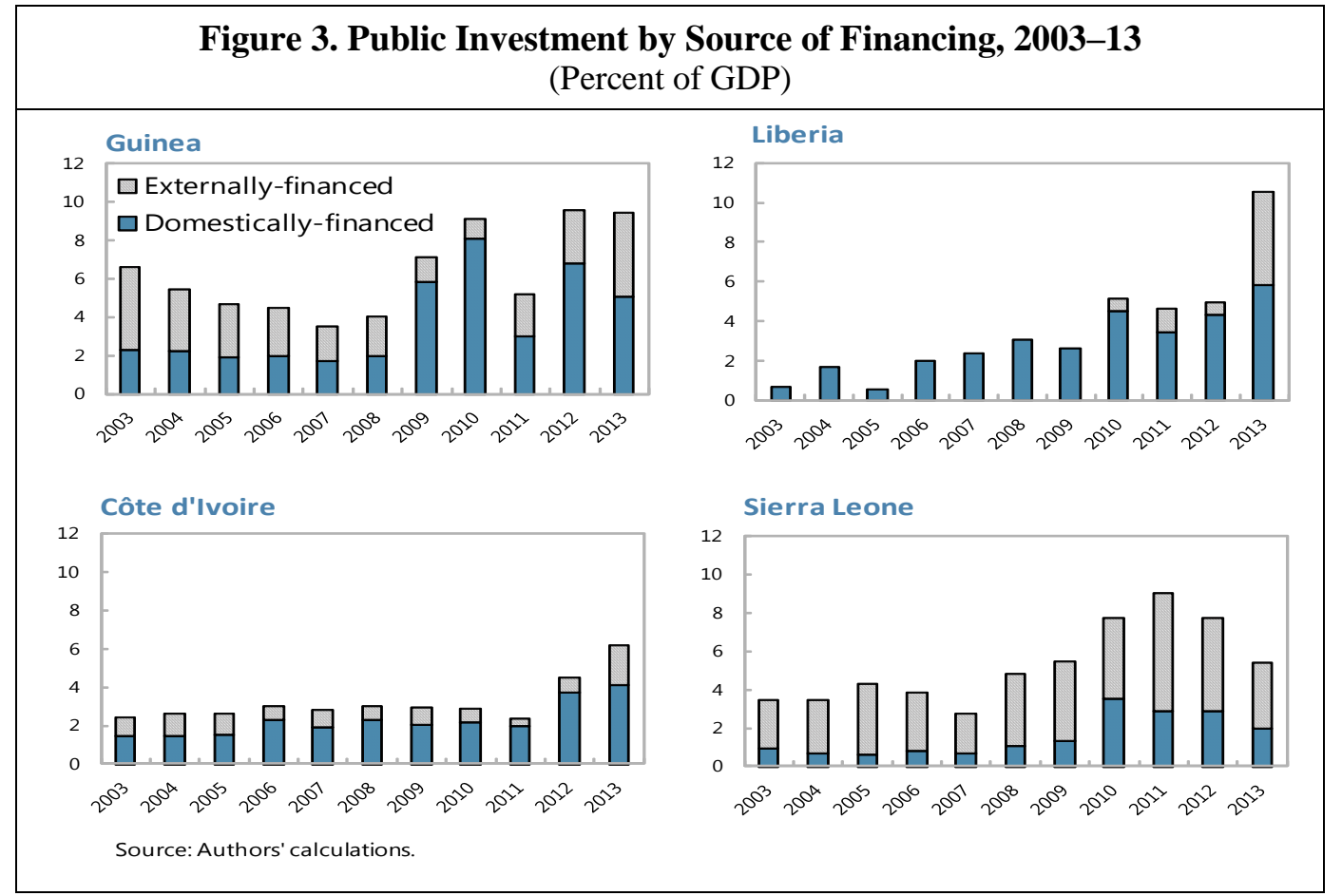

\section{Natural Resource Revenue Projections}

Côte d'Ivoire, Guinea, Liberia, and Sierra Leone are clustered in a resource-abundant region. They are endowed with a variety of exhaustible resources, including diamonds, gold, iron-ore, bauxite, and oil (Box 1). However, these remain largely untapped, helping explain relatively low shares of natural resources fiscal revenue to GDP, total government revenue, and exports, both overall and compared to other resource-rich developing countries (Figure 4). ${ }^{6}$ Mineral extraction is ongoing in all four countries through concession agreements mostly with foreign companies. Oil and gas are currently produced only by Côte d'Ivoire, but there are several petroleum exploration projects underway in other MRU countries as well.

\footnotetext{
${ }^{6}$ For the group of resource-rich developing countries, natural resource exports represent on average 72 percent of total exports and 43 percent of total revenue (IMF, 2012a, Appendix 1, Table 1).
} 


\section{Figure 4. Current Natural Resource Revenue in MRU Countries}

(Percent, average for 2010-12)

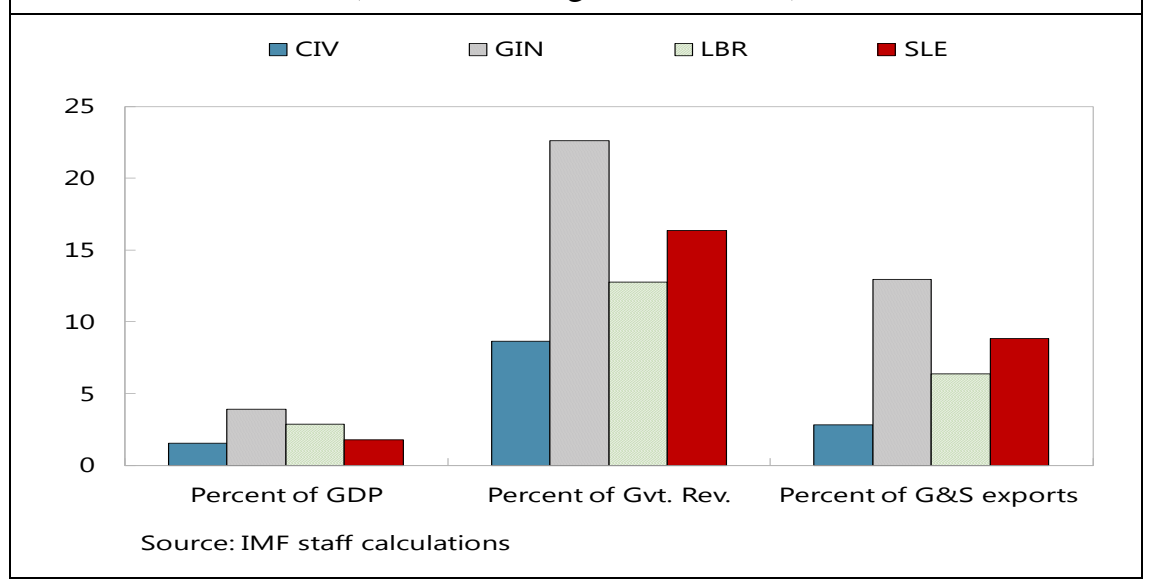

\section{Box 1. Natural Resources Endowments in the MRU Countries}

Côte d'Ivoire's subsoil contains many minerals, but, as of 2013, the country produces mainly oil and natural gas, as well as smaller quantities of gold, manganese ore and diamonds. Unexploited mineral resources include notably iron ore, bauxite, cobalt, and nickel. Proven oil reserves are estimated at 100 million barrels by the U.S. Energy Information Administration (EIA). Owing to limited investment and a variety of technical problems, oil production has fallen to 25,000 barrels a day in 2013 from a peak of 65,000 barrels a day in 2006. Natural gas production began in 2005, with proven reserves estimated at 1 trillion cubic feet. Production of natural gas has averaged 59,000 million of MMBTU over the last decade. Almost all the crude oil is exported, while the natural gas production is sold to domestic electricity producers. Since the end of the political crisis in 2011, several production-sharing agreements have been signed in the petroleum sector. Development and exploration projects are underway spurred in part by the attractive new mining code.

Guinea is by far the richest country in the MRU in terms of identified minerals endowment. Guinea owns about two thirds of the global reserves of bauxite, but its current contribution to the world market remains marginal. The production of gold and diamond is more advanced. Prospects for the mining sector are positive; many projects are underway to expand the production of bauxite and develop ironore. Guinea possesses the largest unexploited iron-ore deposit in the world, in the Simandou range. In addition, a consortium of three companies is undertaking oil exploration. The potential for a substantial increase in revenue inflows from natural resource sector is high provided bauxite and iron-ore production projects come on stream and future concessions are granted transparently and in line with the revised mining code, including through competitive auction procedures.

Liberia is well endowed in natural resources, including iron ore, gold, diamonds, and potentially petroleum. The country resumed production and exports of iron-ore at the end of 2011. The potential for the mining sector is significant, as the government granted several mining concessions in 2010. Iron ore deposits are estimated at more than 2 billion metric tons (bmt) with two more projects expected to come on stream in the medium-term. Prospects in the production of gold look quite positive, and offshore oil exploration has commenced though commercially-viable deposits have yet to be identified.

Sierra Leone possesses significant natural resource potential. Iron-ore production recommenced in 2011 with two large scale projects underway, and others set to follow in the medium term. The country also has significant deposits of diamonds, rutile, bauxite, and gold. Oil exploration is ongoing, although commercially-viable reserves have yet to be identified. Sierra Leone's iron-ore related revenue collection has increased slowly, but it is estimated to pick up mirroring the projected increase in production. The potential from natural resources is quite significant given the wide range of assets. 
We apply the IMF's Fiscal Analysis of Resource Industries model (FARI Model) to generate the contribution of natural resource projects to government revenues in Guinea, Liberia, and Sierra Leone. The model uses the individual projects' fiscal regimes as reflected in the signed concession agreements, their cost structure and production schedule, projected commodity prices adjusted by quality (IMF, World Economic Outlook, April 2014), and other economic assumptions (Figure 5). For Côte d'Ivoire, the methodology used is very similar to that of the FARI model.

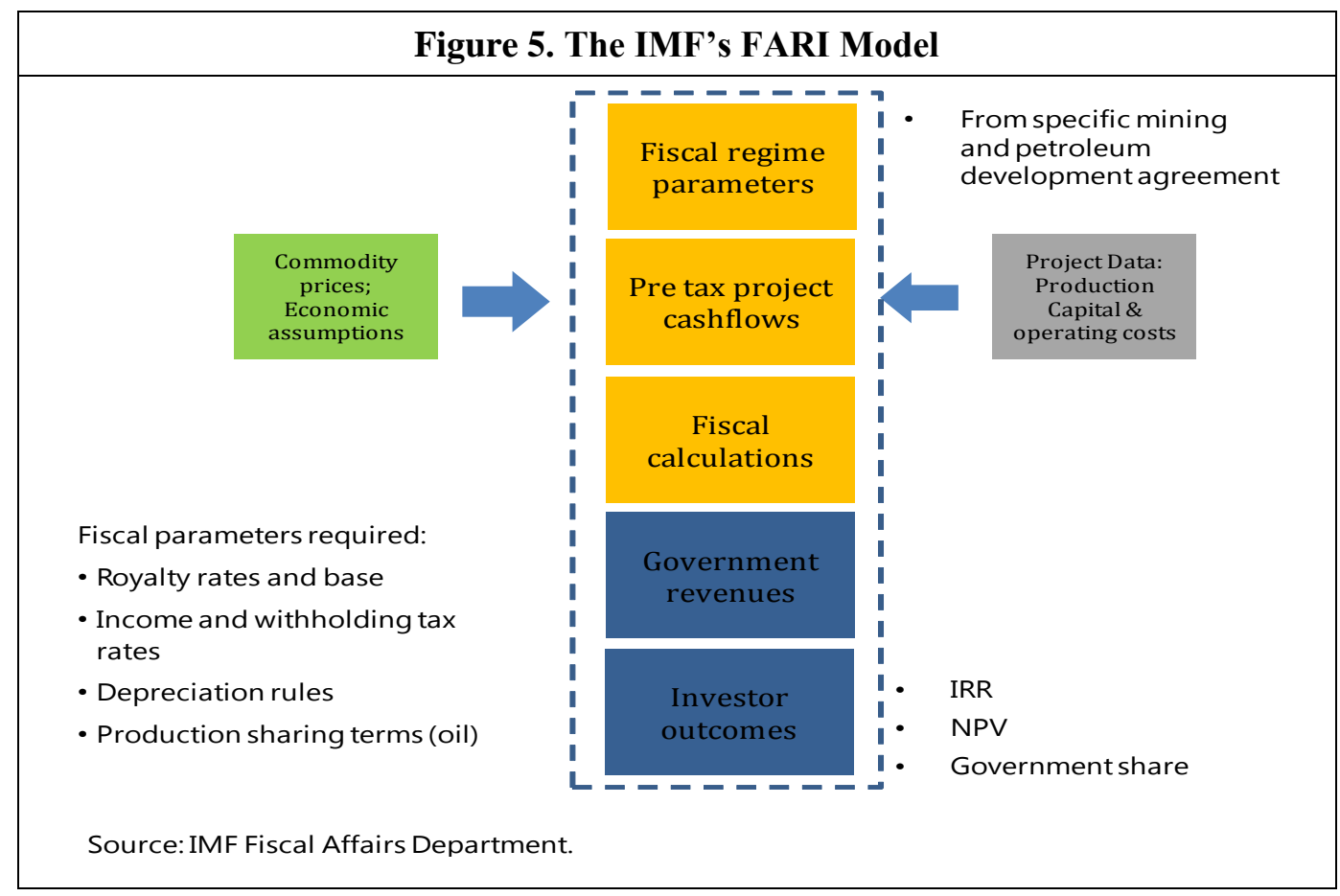

Revenue sources include royalties, withholding income tax on sub-contractors, and corporate income tax. The latter will materialize only in the medium-term when companies become profitable and losses from projects investments have been absorbed. The four MRU countries share broadly similar fiscal regimes, which rely mainly on royalties allowing governments to start collecting revenues immediately when production starts. Royalties are sufficiently attractive (3-5 percent) to attract large foreign companies. Corporate income tax is constrained by the loss-carry-forward provisions embedded either in the concession agreements or in the countries' revenue codes to help investors to absorb project losses in their first years of operations (Appendix 2 presents the fiscal regimes for MRU countries).

For the revenue projections based on the FARI model to materialize, strict enforcement of the fiscal regimes is required. Despite progress made to increase transparency on granting concessions, in some cases terms of individual contracts are unknown or differ from company to company, owing to ad-hoc negotiations. Another constraint is the weak capacity of tax administrations to adequately project the resource revenue, reflecting difficulties in obtaining accurate information from the mining companies on production volumes, product quality, and operating costs. This poses challenges for projecting potential windfalls to the government. 
Nonetheless, most MRU countries are currently working on amending their extractive industries laws with a view to bringing the fiscal regime in line with international best practices.

\section{Scenarios}

We assess future natural resource revenue under two main scenarios: a baseline scenario and an optimistic scenario. The baseline scenario refers to the projection currently underpinning the IMF-supported program macroeconomic frameworks for each country. These tend to be fairly conservative, only incorporating production forecasts associated with projects already under exploitation. The optimistic scenario aims to capture the potential revenue from new projects. It aims for realism, as we only consider projects for which concession agreements have already been signed, investment is ongoing, and will be highly likely to come on stream over the coming years. There is, however, significant uncertainty associated with the pace of investment and the activation of new projects, which in turn has significant implications for the production profile. Further details on the elaboration of resource revenue scenarios can be found in Appendix 2.

Prices are projected using commodity price projections for 2014-19 from the IMF's World Economic Outlook (WEO, Spring 2014). ${ }^{7}$ In the case of iron-ore, prices are adjusted accordingly to reflect content quality and special pricing arrangements. After the end of the WEO projection period, we assume that prices remain constant in real terms.

Finally, although the baseline scenario aims at representing a lower bound on projected resources output, we look into the impact of negative resource price shocks on resource revenue, with a view to reflecting recent volatility associated with the slowdown in emerging market economies. An adverse resource revenue scenario caused by a drop in iron ore prices for Liberia is simulated to demonstrate the downside fiscal risk of volatile resource commodity prices. In this scenario, prices in 2015-16 were adjusted downward by 60 percent (i.e., twice the historical standard deviation), with a gradual recovery reaching 90 percent of the latest WEO prices by year five.

Baseline scenario. Overall, projections for the four countries show that under the baseline scenario, resource revenue as a share of GDP is small (Figure 6). Resource revenue remains at around 2.5 percent of GDP over the projection period. While this still represents a nonnegligible share of total revenue (about 16.8 percent of total revenues on average), this will not

\footnotetext{
${ }^{7}$ Both scenarios are thus based on the pre-Ebola outbreak situation for the four MRU countries. Evidently the post-Ebola resource production profiles and macroeconomic frameworks are likely to be quite different. The Ebola crisis is having a significant impact on growth and is disrupting current mining output in Liberia and Sierra Leone and will likely affect medium-term production profiles as key investment is delayed. While there is too much uncertainty at the moment to attempt to establish a new set of macroeconomic projections, the present exercise should be understood as illustrative of the steps that would have to be followed in other resource-rich fragile countries or in the MRU after the current Ebola outbreak is contained.
} 
suffice to finance the transformative investments that country authorities are envisaging; external borrowing would be required.

Optimistic scenario. The optimistic scenario captures the upper bound for resource output and shows, provided fiscal terms are applied as projected, resource revenue may potentially be larger than could productively be absorbed under current investment plans. However, long project gestation periods imply that the upside would not materialize within the next decade in all countries. For Guinea, provided the development of the Simandou projects unfolds as planned, iron ore revenue could reach almost 20 percent of GDP by 2026.

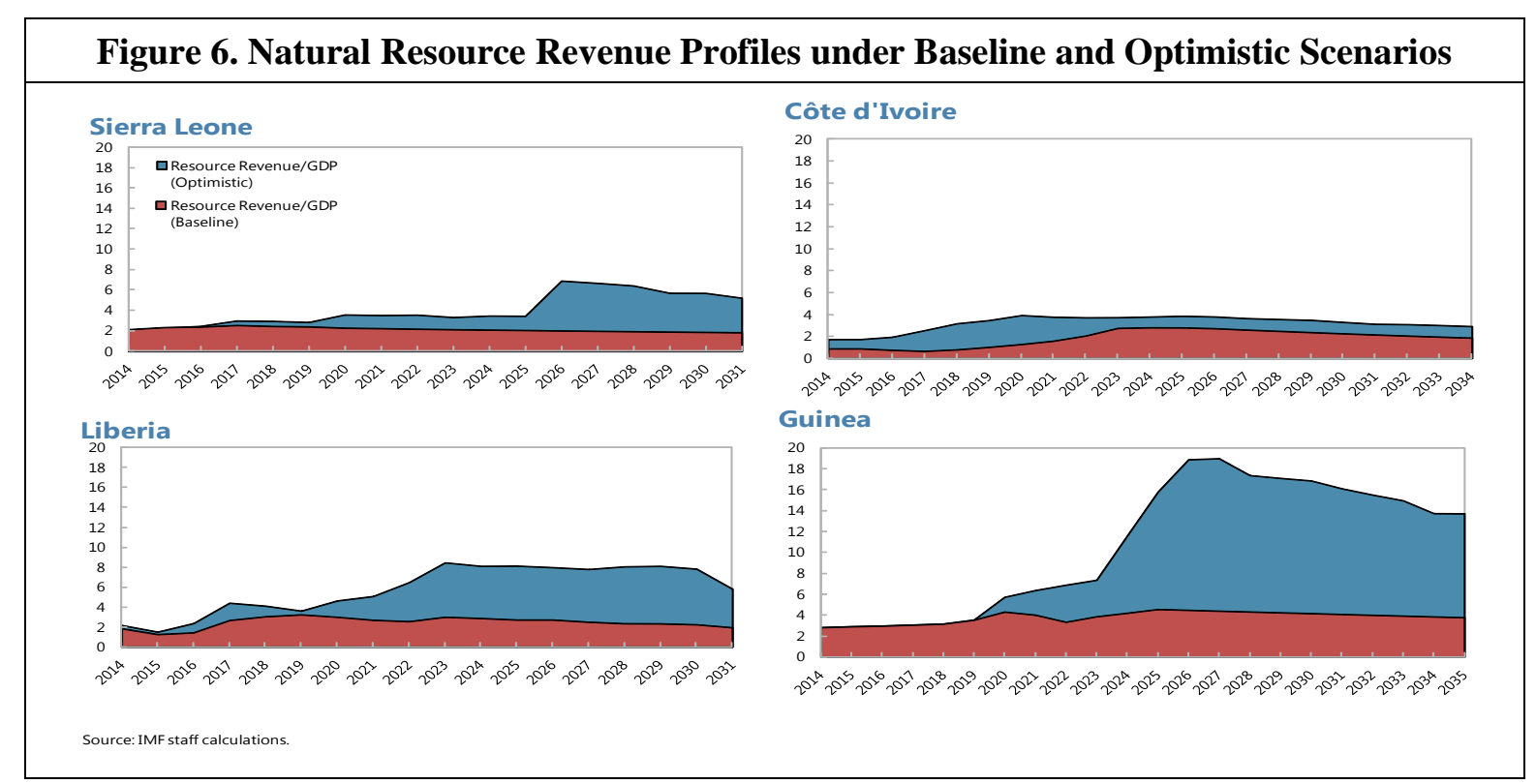

However, the resource revenue projections, particularly for mining countries, are subject to significant uncertainty. Figure 6 shows that the resource revenue profiles for the three mining countries, Guinea, Liberia, and Sierra Leone, under the optimistic scenario are much more volatile than the profile for Côte d'Ivoire, an oil producing country. This is due to the lumpy profile of the projects expected to come on stream over the medium term. Further, any delay or re-phasing of production profiles will have a large impact on revenue projections. Finally, iron ore prices are volatile, adding to the substantial uncertainty regarding production quantities.

\section{FisCAL FraMEWORKS FOR MRU COUNTRIES}

A major build up in public investment associated with windfalls from exhaustible resources is at the heart of MRU countries' development agendas. Although public investment, including in infrastructure and human capital, has been found to be beneficial for growth, spending natural resource revenue can also lead to Dutch disease symptoms (e.g., Gelb, 1988, Sachs and Warner 1999, 2001, and van der Ploeg, 2011).

Until recently, the conventional policy advice for resource-rich countries has been mostly guided by the Permanent Income Approach (PIH); see e.g., Barnett and Ossowski (2003) and Davis et al. (2001). The PIH requires that countries keep spending at a level equal to the 
interest earning on the present value of the estimated resource wealth, with the windfall saved in financial assets to guarantee intergenerational consumption and fiscal sustainability.

Recent work, however, has questioned the relevance of the PIH for resource-rich developing countries (RRDCs) where poverty is high, capital scarce, and access to international capital markets limited. In such circumstances, some frontloading of consumption towards poorer current generations is desirable, while the bulk of resource revenue ought to be either used for investment or saving for future generations (Collier et al., 2010, IMF, 2012a, van der Ploeg and Venables, 2011).

Two key challenges for RRDCs are (i) deciding how much of the resource revenue to consume or invest in the short term, and how much to save, given that natural resources are exhaustible but the production horizon is uncertain; and (ii) finding ways to delink spending from volatile revenue to avoid boom-bust cycles. On the first challenge, too aggressive frontloading of current consumption or investment can lead to Dutch Disease and jeopardize debt sustainability, particularly in the presence of capacity or absorption constraints. In this regard, Berg et al. (2013) develop a general equilibrium model to assess the macroeconomic impact of scaling up public investment and propose a sustainable investing approach implying a gradual and cautious buildup of public capital to ensure macroeconomic stability and long-lasting growth benefits from investing the resource windfall. Recognizing the importance of absorption and capacity constraints in low-income countries, Collier et al. (2010) propose a measured approach to build up capacity to manage investment ("investing in investment").

To address the second challenge, Baunsgaard et al. (2012) and IMF (2012a) propose a set of fiscal rules tailored to the various circumstances of RRDCs, recognizing that the resourceproduction horizon is a key variable. Countries with relatively short reserve horizons, where issues of exhaustibility are dominant, should target a non-resource primary balance (NRPB) designed to ensure fiscal sustainability. The calibration of the NRPB paths could be determined through alternative theoretical frameworks (PIH, modified PIH or others), and could be supplemented by a price-based rule or an expenditure rule. For countries with long reserve horizons (i.e., where the key issue is to avoid boom-bust cycles), a structural primary balance rule $(\mathrm{SPB})$ based on a price-based rule may be appropriate.

At present, MRU countries are managing their natural wealth in ad-hoc ways. In the case of Côte d'Ivoire, Liberia and Sierra Leone, all the extractive revenues collected including one-off payments are spent. Given current investment plans and limited resource revenue in the baseline scenario, there would be no savings for future generations. On the other hand, in 2012 Guinea introduced a Special Investment Fund (SIF), which was created with a US\$250 million initial endowment from the US\$700 million one-off receipt collected. Given Guinea’s shortterm needs, the SIF will be depleted by end-2014. Liberia and Sierra Leone are in the early stages of considering adopting a fiscal rule to manage resource wealth.

The institutional contexts of MRU countries (weak institutions, poor governance, and low quality of data), type of natural resources (mostly minerals) limit their options regarding the 
choice of a fiscal rule. For instance, a price-based rule (PBR) is of little use when most of the uncertainty/volatility relates to production volumes. Calculation of the structural primary balance using reference prices also requires good data and can pose challenges for fragile countries where economic cycles are erratic. Finally, the high poverty and capital gaps make long-term fiscal sustainability concerns less pressing in the MRU countries, at least in the short to medium run.

In light of these considerations, and taking into account the uncertainty surrounding the size and horizon of natural resources production, we argue that the focus in the MRU countries should be on managing revenue volatility and avoiding fiscal pro-cyclicality in the short to medium term. This implies the recourse to a non-resource balance target rule (NRB) as fiscal anchor rather than to a rule based on the non-resource primary balance (NRPB), which places more emphasis on long-term fiscal sustainability. In addition, the NRB rule is easy to measure and implement once calibrated for a particular country (although its calibration requires detailed projections of resource revenue, debt sustainability, and investment capacity).

Therefore, in this paper, we investigate the macroeconomic implications of applying a rule based on a sustainable non-resource balance target (NRB) to derive the path of public investment in MRU countries. We also use non-resource primary balance (NRPB) fiscal rules based on the well-known PIH framework as a benchmark, to highlight the trade-offs involved with adopting either natural resources management framework.

The sustainable non-resource deficit target rule is akin to Botswana's Sustainable Budget Index. ${ }^{8}$ Under the proposed rule (1), total expenditure in real terms is capped by a sustainable NRB deficit target, where the deficit target is a function of projected resource revenue and is consistent with medium-term debt sustainability, with current spending fully financed by nonresource revenue. In this context, resource revenue is allocated to infrastructure and, possibly, human capital spending, with any surplus being accumulated in a natural resource fund.

$$
T E=\frac{N R R}{1-N R B}
$$

Where TE is total expenditure (i.e., current and capital); NRR is the non-resource revenue (tax, non-tax, and grants); and NRB is the non-resource deficit target (expenditure less non-resource revenue as a share of expenditure, in percent). The NRB deficit target reflects the temporary increase in capital spending financed by borrowing (mainly external) during the period in which the stream of resource revenue is limited. As an example, if NRR is 75 units and the sustainable NRB deficit target is 25 percent, then total expenditure is capped at 100.

Calibration under the baseline scenario (Figure 7). The NRB deficit target was calibrated taking into account the investment paths associated to the MRU countries' current

\footnotetext{
${ }^{8}$ Botswana's Sustainable Budget Index requires all current spending to be covered by non-resource revenue, with diamond revenue allocated to public investment and health and education, or saved in the Pula Fund.
} 
macroeconomic frameworks (which implicitly take into consideration the countries' development agenda and their absorptive capacity), debt sustainability analyses, and the natural resource revenue stream projected in the baseline scenario. ${ }^{9}$

The sustainable NRB target for Liberia was estimated to average 20 percent of the NRR during 2014-17, which would allow scaling up capital spending to an annual average of 9.8 percent of GDP during that period. To ensure fiscal sustainability and take into account the horizon of the commodity resources, the NRB target is then set to decline over time by one percent per year. This brings the annual average investment path (NRB target) to 7.1 percent of GDP in 2017-25 and around 5 percent of GDP thereafter. The latter represents an investment level above the near 3.7 percent of GDP average during 2009-12.

In the case of Côte d'Ivoire, the NRB target deficit was estimated to average 25 percent of the NRR stream for 2014-17, or an annual investment level equal to 7.9 percent of GDP, up from an annual average of 2.2 percent of GDP, which needs to be reduced annually by 1 percent in line with the debt limits implied by the debt sustainability analysis.

Optimistic scenario. Given that the potential for larger revenue flows in the case of Côte d'Ivoire is quite limited, we maintained the rule calibration applied in the baseline scenario. For Liberia, however, we evaluated the option to relax the rule to accommodate higher public investment, within the limit of absorptive capacity. The NRB deficit target was increased to 25 percent of the projected NRR for the 2014-17 equal to an annual capital spending of 12 percent of GDP. As in the baseline, the NRB deficit target needs to be reduced still by 1 percent bringing capital spending to an annual average of 9.0 percent of GDP between 2018 and 2025 and to 6.6 percent of GDP thereafter.

Comparing the NRB rule to the PIH and MPIH (Figure 7). In Liberia, in the baseline scenario, the NRB rule allows to frontload investment while still smoothing spending over time. Given relatively low natural resource revenue, the investment path consistent with the PIH-based rule is well-below that envisaged by the authorities. While the modified PIH would allow Liberia and Côte d'Ivoire to front-load critical investment projects, it would require substantial fiscal adjustments after the initial investment buildup in order to return to an investment path consistent with the rule. In the optimistic scenario, with larger resource revenue the PIH and the modified PIH produce more sensible results, though the NRB allows for a larger frontloading of public investment. ${ }^{10}$

\footnotetext{
${ }^{9}$ Given that the revenue profiles for the three mining countries (Guinea, Liberia, and Sierra Leone) exhibit similar characteristics, in the rest of this section we only present results for Liberia and Côte d'Ivoire.

${ }^{10}$ Under the baseline scenario, for Liberia, the investment path based on the PIH equals the rate of return on the PV of the projected natural resource wealth (about 1.8 percent of GDP), plus the investment financed with the government's own resources (about 2 percent of GDP). For Côte d'Ivoire, under the PIH, public investment is projected to decrease gradually but to equal on average the sum of the annual return on the PV of resource wealth (equal to 2.3 percent of GDP) and of grant-financed investment (1.3 percent of GDP). In the optimistic scenario, for Liberia the pure PIH estimate is 4.3 percent of GDP, raising the investment path to an average of 10.3 percent of GDP during 2015-19. For Côte d'Ivoire, under PIH the pure estimate of public investment ratio is only slightly higher than under the baseline at 3 percent of GDP.
} 


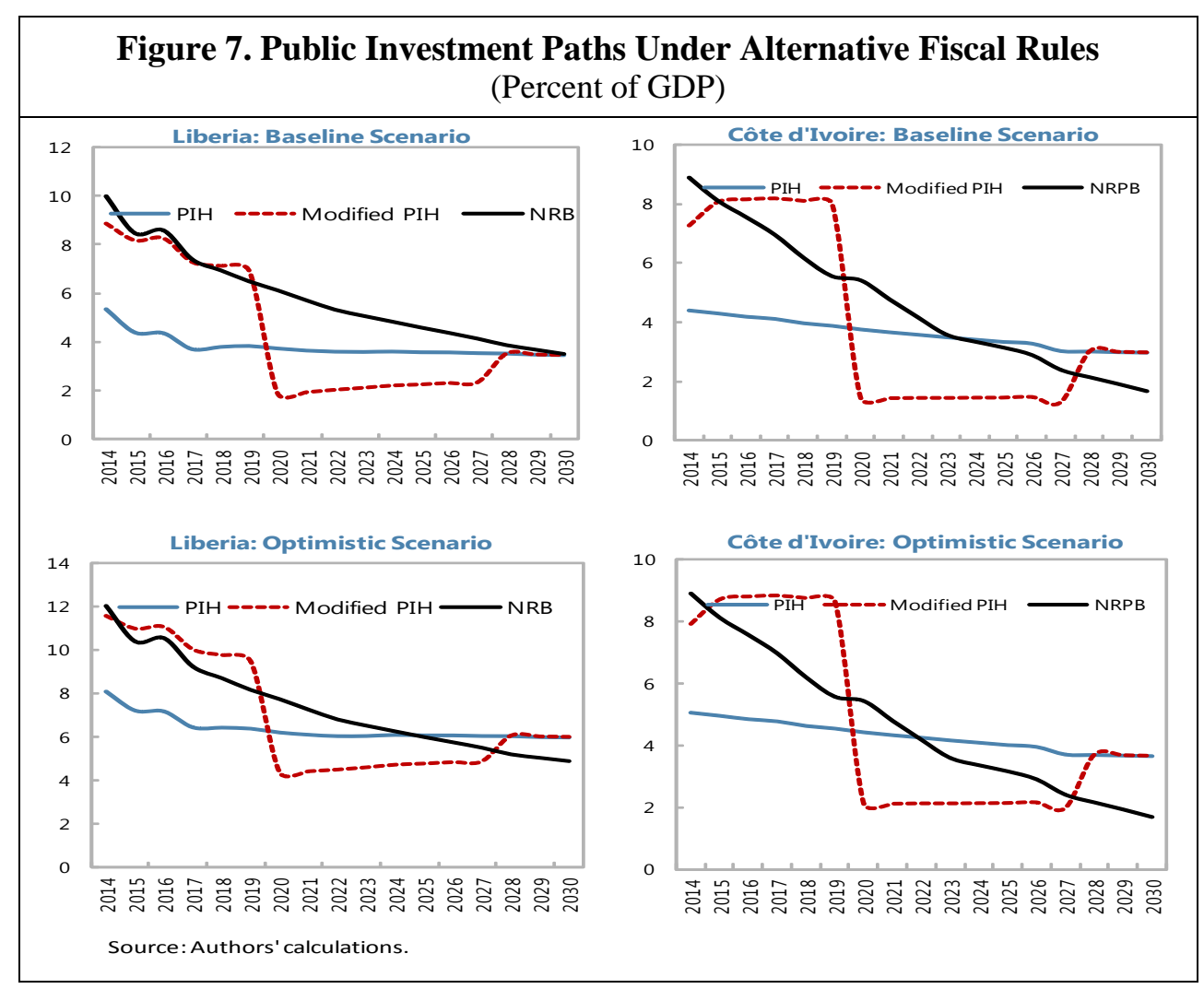

\section{THE DIGNAR APPLICATION}

To assess the macroeconomic and fiscal implications of the investment paths derived in the previous section under various fiscal rules, we modify the DIGNAR model and apply it to Liberia, Côte d'Ivoire, Guinea, and Sierra Leone. The model combines the debt sustainability framework developed in Buffie et al. (2012) with the natural resource model in Berg et al. (2013). It is particularly well-suited for assessing the investment-growth nexus together with debt sustainability in resource-rich developing countries that, like the four listed above, intend to scale up public investment, financed by a combination of borrowing and resource revenues.

\section{A. Model Description}

DIGNAR is a real (i.e., there are no nominal rigidities) dynamic general equilibrium model of a small open economy consisting of households, firms, and a fiscal authority. The description here focuses on the model's key features; the complete specification and calibration can be found in Appendix 3.

Households. The model is composed of two types of households: i) forward-looking, optimizing households with access to financial and capital markets who can smooth their consumption across periods; and ii) hand-to-mouth households without access to financial and capital markets who must consume all their disposable income every period. (See (5)-(8) for the utility functions and budget constraints of the households in Appendix 3). A large share of hand-to-mouth households is a distinguishing feature of low-income countries. This has the 
important policy implication that resource revenue transferred directly to these households can immediately boost their level of consumption. ${ }^{11}$

Firms. The model has three production sectors: nontraded goods, non-resource traded goods, and natural resources. Since our interest in the resource sector lies in the fiscal approaches to managing resource revenues, we assume that natural resource-producing firms are owned by foreigners, its production does not employ labor and capital, and all resource output is exported. Total resource output is subject to a royalty tax. ${ }^{12}$

Firms in the two non-resource productions sectors are perfectly competitive. They produce output using Cobb-Douglas technology with constant returns to scale of capital and labor. Public capital is an input to production and increases the productivity of private inputs.

To capture the potential Dutch disease from spending resource revenues, total factor productivity (TFP) in the traded goods sector is subject to learning-by-doing externalities. Spending resource revenues domestically can result in real appreciation, hurting the competitiveness of the traded goods sector and lowering traded output. Following Berg et al. (2010) and van Wijnbergen (1984), TFP in the traded goods sector is assumed to depend on its last-period output. With some persistence in the TFP process, Dutch disease can linger before productive public capital is sufficiently built up to reverse the negative impact on traded output. ${ }^{13}$

Government. The government each period collects taxes, receives foreign grants and aid, and issues debt to finance its expenditures on government consumption, public investment, transfers to households, and debt service. As in Buffie et al. (2012), the model distinguishes among domestic debt, external commercial debt, and external concessional debt. The path of external concessional debt, taken exogenously, is consistent with the projections used in the IMF's Debt Sustainability Analysis for the country under consideration. The model also

\footnotetext{
${ }^{11}$ Spending resource revenues on productive public investment can increase consumption of both types of households. However, it works indirectly by boosting private sector productivity and hence the wage rate due to more productive capital. A higher wage rate increases households' income and private consumption. Compared to spending resource revenue on public investment, direct revenue transfers increase private consumption of the hand-to-mouth immediately without the delay in building up public capital.

${ }^{12}$ In reality, tax schemes on the resource production can be complicated. The paths of royalty rates used in simulations are backed out to target resource revenues to GDP ratios, obtained from the simulations of the FARI model.

${ }^{13}$ Learning-by-doing externalities can both reduce and enhance private sector productivity, depending on traded output responses to resource spending. Under our assumption that part of the resource revenues is spent on nontraded goods, spending resource revenue leads to real appreciation, which lowers the productivity of the traded good sector. Later as public capital is built up due to increased investment spending, the externalities enhance private productivity of both sectors with more productive public capital.
} 
includes a resource fund that holds international financial assets and serves as a stabilization buffer. $^{14}$

Fiscal Policy. The path of public investment is given exogenously and is implied by the different fiscal rules discussed in Section IV. For all four countries, the initial transfers to GDP ratios are significantly below one percent. In the experiment with increasing transfers, we assume a path that exogenously rises from one percent to two percent of GDP, with the pace of increase determined by each country's resource revenues. We assume that government consumption follows its trend growth path in all simulations.

Given the exogenous paths of the natural resource sector and the fiscal authority, any revenues in excess of what is allocated to public investment under the various fiscal rules are accumulated in a resource fund. When economies are hit by negative resource revenue shocks (which can come from either lower quantity or prices), the resource fund is drawn down to support pre-specified spending levels. If the resource fund does not have sufficient savings to cover the revenue shortfall, the government utilizes external commercial borrowing. We assume that limited financial development in the domestic debt markets forces the government to borrow on the external commercial market when required. Thus, the accumulation of external commercial debt is endogenously determined. ${ }^{15}$ Increased debt must eventually be paid for with higher consumption taxes.

Investment Efficiency and Absorptive Capacity Constraints. One main concern for scalingup public investment in developing countries is the general low efficiency of investment spending (see Box 2 for the assessment of public investment efficiency in the four countries). In the model, public investment spending is not fully efficient, so one dollar of investment is converted into less than one dollar of installed public capital. We also assume that there are absorptive capacity constraints, such that scaling up investment spending too quickly can cause further decreases in investment efficiency.

\section{B. Fiscal Approaches}

Resource Revenue Scenarios. The simulations for all four countries are conducted under baseline and optimistic scenarios of resource revenue profiles, as discussed in Section IV and shown in Figure 7.

\footnotetext{
${ }^{14}$ Van den Bremer and van der Ploeg (2013) distinguish among three types of resource funds often encountered in reality: 1) an intergenerational fund (such as a sovereign wealth fund), which mainly saves current resource revenues to smooth benefits across generations, 2) a liquidity fund, motivated by precautionary saving to selfinsure against large future negative shocks to volatile revenues, and 3) an investment fund, which uses resource revenues to undertake domestic public investment projects. The resource fund modeled here is a combination of a liquidity fund and an investment fund.

${ }^{15}$ This implies that the debt trajectory generated by the simulations using the DIGNAR model may not be consistent with the debt path from the debt sustainability analysis, which is generated using a different framework that does not account for the general equilibrium interactions between fiscal and macroeconomic variables.
} 


\section{Box 2. Public Investment Efficiency in MRU Countries}

Achieving inclusive growth and sustainable poverty alleviation through successful scaling up of public investment hinges heavily on sound public institutions. Recent studies point to the prominence of the quality or efficiency of public investment for raising the productivity of public capital and buttressing economic growth (IMF 2009, Dabla Norris et al., 2011, Gupta et al., 2011).

The Public Investment Management Index (PIMI, Dabla Norris et al., 2011) captures countries' public investment efficiency through their capacity to adequately select, implement, and evaluate projects. Using this index (unfortunately not available for Liberia), aside from Côte d'Ivoire the MRU countries perform poorly compared to low income countries and other countries in the SSA region. (Box Figure 1).

Another indicator of the quality of budget institutions is given by the Public Expenditure and Financial Accountability assessment (PEFA)

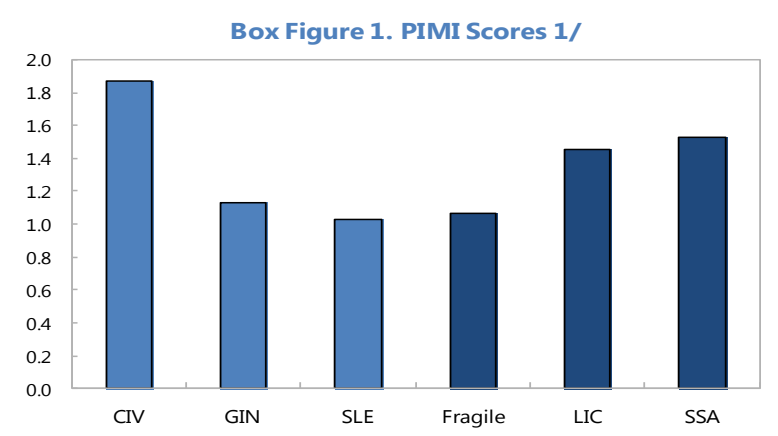

Source: Dabla-Norris et al. (2011). Note: PIMI Index value range from zero (poorest) to 4 (highest). survey (unavailable for Guinea). Looking at indicators capturing the effectiveness of procurement systems and of internal controls for non-salary expenditures, MRU countries obtain low scores for most categories. Any scaling up strategy in these countries will thus need to go hand-in-hand with improvements in public finance management (PFM) systems, which are pivotal for selecting projects with the highest growth dividend and implementing them in a timely fashion. This will help preserve consistency of public investment scaling-up with debt sustainability (Gupta et al., 2014).

Box Table 1. Public Expenditure and Financial Accountability (PEFA)

\begin{tabular}{|c|c|c|c|c|}
\hline & Côte d'Ivoire & Guinea & Liberia & Sierra Leone \\
\hline $\begin{array}{l}\text { Transparency, competition and complaints mechanisms in } \\
\text { procurement } \\
\text { (i) Transparency, comprehensiveness and competition in the legal } \\
\text { and regulatory framework }\end{array}$ & C & $\ldots$ & C & $C+$ \\
\hline $\begin{array}{l}\text { (ii) Use of competitive procurement methods } \\
\text { (iii) Public access to complete, reliable and timely procurment } \\
\text { information } \\
\text { (iv) Existence of an independent administrative procurement } \\
\text { complaints system }\end{array}$ & C & $\ldots$ & B & $\mathrm{C}$ \\
\hline Effectiveness of internal controls for non-salary expenditure & $\mathrm{D}+$ & $\ldots$ & $\mathrm{C}+$ & $\mathrm{C}+$ \\
\hline $\begin{array}{l}\text { (i) Effectiveness of expenditure commitment controls. } \\
\text { (ii) Comprehensiveness, relevance and understanding of other } \\
\text { internal control rules/ procedures } \\
\text { (iii) Degreeof compliance with rules for processing and recording } \\
\text { transactions }\end{array}$ & C & $\ldots$ & $C$ & B \\
\hline Effectiveness of internal audit & $\mathrm{D}+$ & $\ldots$ & $\mathrm{D}+$ & $D+$ \\
\hline
\end{tabular}

Source: PEFA Program, 2013

Note: the PEFA index assesses public financial management performance across a wide set of countries. Scores range from $A$ to $D$, with $A$ being the highest score and referring to the best practice, while $D$ corresponds to the lowest score and applies if the requirements for any higher score are not met. This table displays only the elements related to public investment. Country scores correspond to following years: Sierra Leone, 2010; Liberia, 2012; Côte d'Ivoire, 2008.

Two main approaches for all four countries. Across the four countries, we analyze macroeconomic and fiscal implications of directing natural resource revenue to public investment and to household transfers. In the first approach, public investment is scaled up as implied by the NRB rule discussed in the previous section, and transfer spending as a share of GDP is maintained at its initial level. In the second approach, transfers as a share of GDP 
increase gradually, stabilizing at 1 to 2 percent of GDP with an equal reduction in the level of public investment spending, so that the combined spending on transfers and investment is the same in both scenarios.

A conservative investing approach. We also simulate a public investment path implied by the conventionally-advised PIH for Liberia and Côte d'Ivoire to see whether a very conservative investment approach could also be suitable. Relative to the investment paths with the nonresource balance rule, public investment is much lower, and the government cannot undertake major investment projects.

\section{Simulation Results}

Detailed explanations are provided for Liberia, and full simulation results for the other three countries are presented in Appendix 3.

\section{Effects of a public investment scaling-up (Figure 8):}

- Under the baseline scenario, (left column), the front-loaded investment path has elevated spending levels at 10-11 percent of GDP between 2014 and 2017. It then gradually decreases to about 6 percent of GDP starting in 2022 so as to maintain public capital at about 80 percent above the trend growth path. More public capital increases the returns to private capital and labor, resulting in higher non-resource GDP. Since resource revenues are low-below 3 percent of GDP for most years - the investment path requires additional borrowing, with no savings in the resource fund until the very end of the projection period. The path of total debt increases from 32 percent to almost 60 percent of GDP, reflecting higher levels of both concessional debt and external commercial debt. Higher public debt triggers a two percentage point increase in the consumption tax rate to stabilize debt growth. Higher consumption tax rates dampen private consumption, offsetting some of the higher consumption accrued from faster non-resource GDP growth.

- Under a conservative investment scenario based on the PIH rule, public investment is kept below 4 percent of GDP in most years. Even with relatively paltry resource revenues, the resource fund rapidly accumulates savings, reaching 32 percent of GDP by 2026. This accumulation comes at a cost of lower non-resource GDP growth and private consumption as revenue is diverted toward savings and away from investment or transfer spending. Investment is spent almost entirely on replenishing depreciated capital.

- The real exchange rate, however, appreciates much less severely in the PIH case than in the baseline case, as most resource revenues are invested in external financial assets. Dutch disease (a decline in traded output) is not present with the PIH spending rule, while traded output experiences a fall relative to the level in the trend-growth path in all other simulated fiscal approaches.

- Turning to the optimistic resource revenue scenario (right column), the public investment levels under the non-resource based rule are higher than under the baseline scenario, reaching 13.4 percent of GDP in 2016. The qualitative differences among various fiscal 
approaches observed under the baseline scenario hold under the optimistic scenario. With more resource revenue, especially after 2022, the resource fund manages to accumulate significant savings over time, reaching 12.4 percent of GDP in 2026.

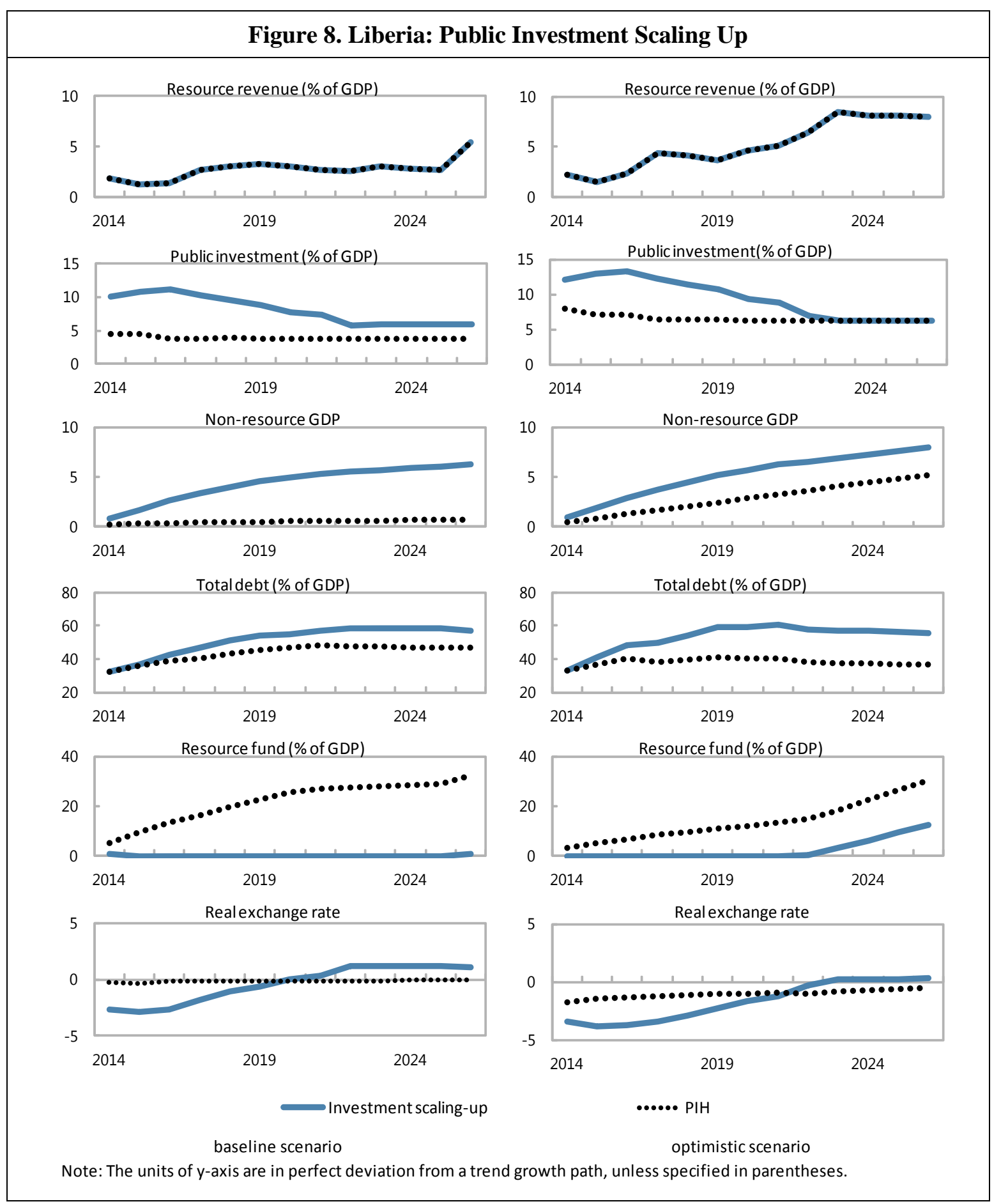

\section{Adding social transfers to the basic model (Figure 9):}

- Instead of spending resource revenue entirely on public investment, the government can transfer a portion of that revenue directly to households, as a social transfer. To see the 
tradeoffs between public investment and direct transfers, we simulate an increase in transfers while offsetting public investment spending by the same amount. Under the baseline scenario, transfers gradually increase to 1.5 percent of GDP, and public investment only scales up to 10 percent of GDP between 2014 and 2016 before stabilizing at 5 percent of GDP. ${ }^{16}$

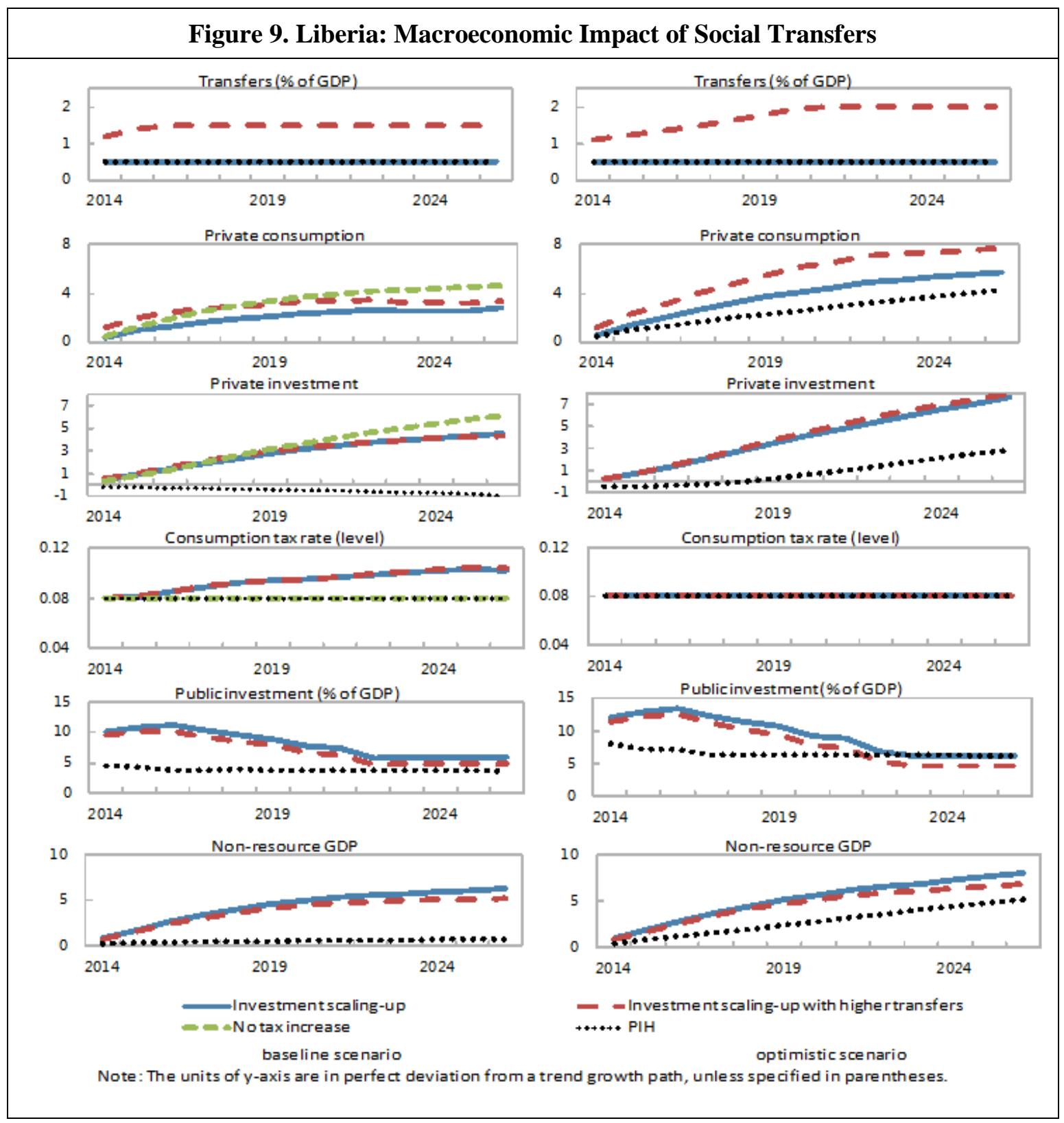

- Tradeoffs between public investment and transfers to households. The immediate benefit of raising transfers is higher private consumption. The small magnitude of the private consumption increase is due to the small scale of the assumed transfers increase. With less

\footnotetext{
${ }^{16}$ The initial level of transfers is based on the actual average share of transfers in GDP in the four countries,
} which, at the moment, are mostly financed by donors (Monchuk, 2014). 
public investment, however, public capital builds up less and there is a smaller rise is nonresource GDP. The diminished non-resource GDP growth does have a negative effect on private consumption, but it is outweighed by the positive impact of the transfer on the private consumption of hand-to-mouth households (the majority of households in the model). Less public capital formation reduces the incentive for optimizing households to invest in private capital, lowering the path of private investment. However, if the share of optimizing households were to increase, private investment would likely increase as households direct the cash transfer toward investment rather than higher consumption.

- Fiscal adjustment and debt sustainability. The fact that the government requires significant borrowing to support the front-loaded investment scaling-up suggests that debt sustainability can be a concern if fiscal adjustments are difficult to implement. Weak institutions in fragile countries and political instability may hinder non-resource revenue mobilization. We also simulate a scenario with no tax adjustment for the same magnitude of investment scaling up to assess the implications of inflexible fiscal policy on debt sustainability. Private consumption and investment are both higher in the case without a consumption tax rate increase, although debt accumulates to 70 percent of GDP by 2025 with no sign of stabilizing. Though the model does not build in sovereign default risk, the simulations suggest that there are significant debt sustainability issues in this scenario.

Public investment efficiency and absorptive capacity (Figure 10). The efficiency of public investment, which is 50 percent under the baseline scenario, falls to about 40 percent in the first few years under the optimistic scenario. This follows from our assumption that aggressive scaling up can be bound by constraints like weak management capacity, supply bottlenecks, and institutional quality issues (also see Box 5).

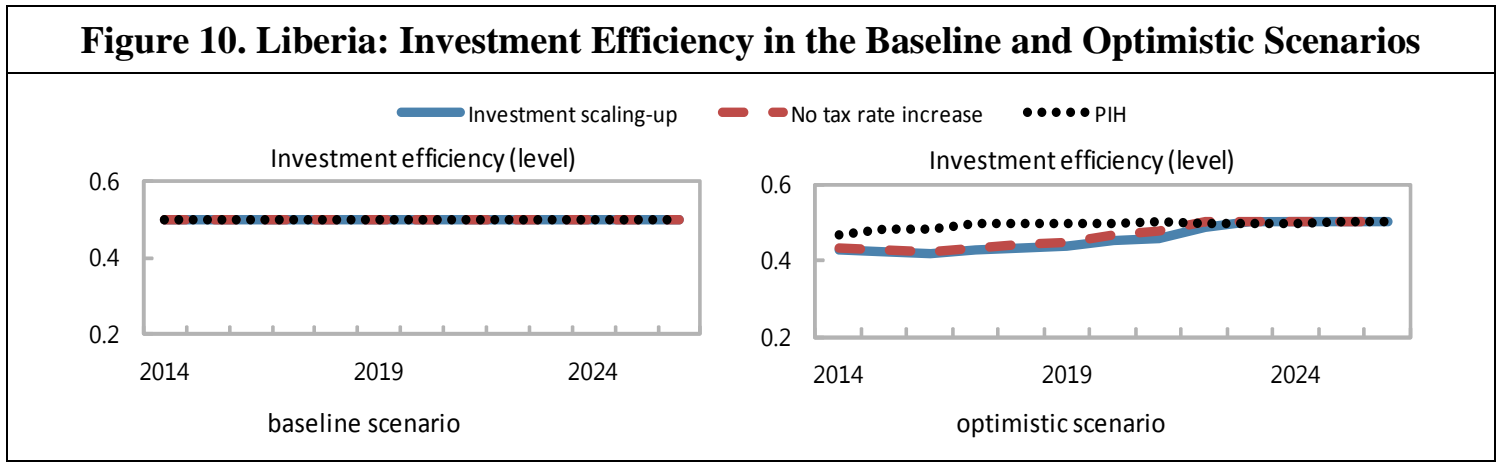

Adverse resource revenue scenario (Figure 11). While the resource revenue projections embedded in the baseline scenario are quite conservative, especially the assumption on production quantity, the volatile nature of resource prices is not accounted for. To see how the economy may react to a negative resource price shock, we simulate an adverse resource revenue scenario wherein resource revenues drops below 1 percent of GDP from 2015 to 2017 and stays below 2 percent of GDP afterward. The blue lines depict the responses with the same investment path implied under the NRB rule. 


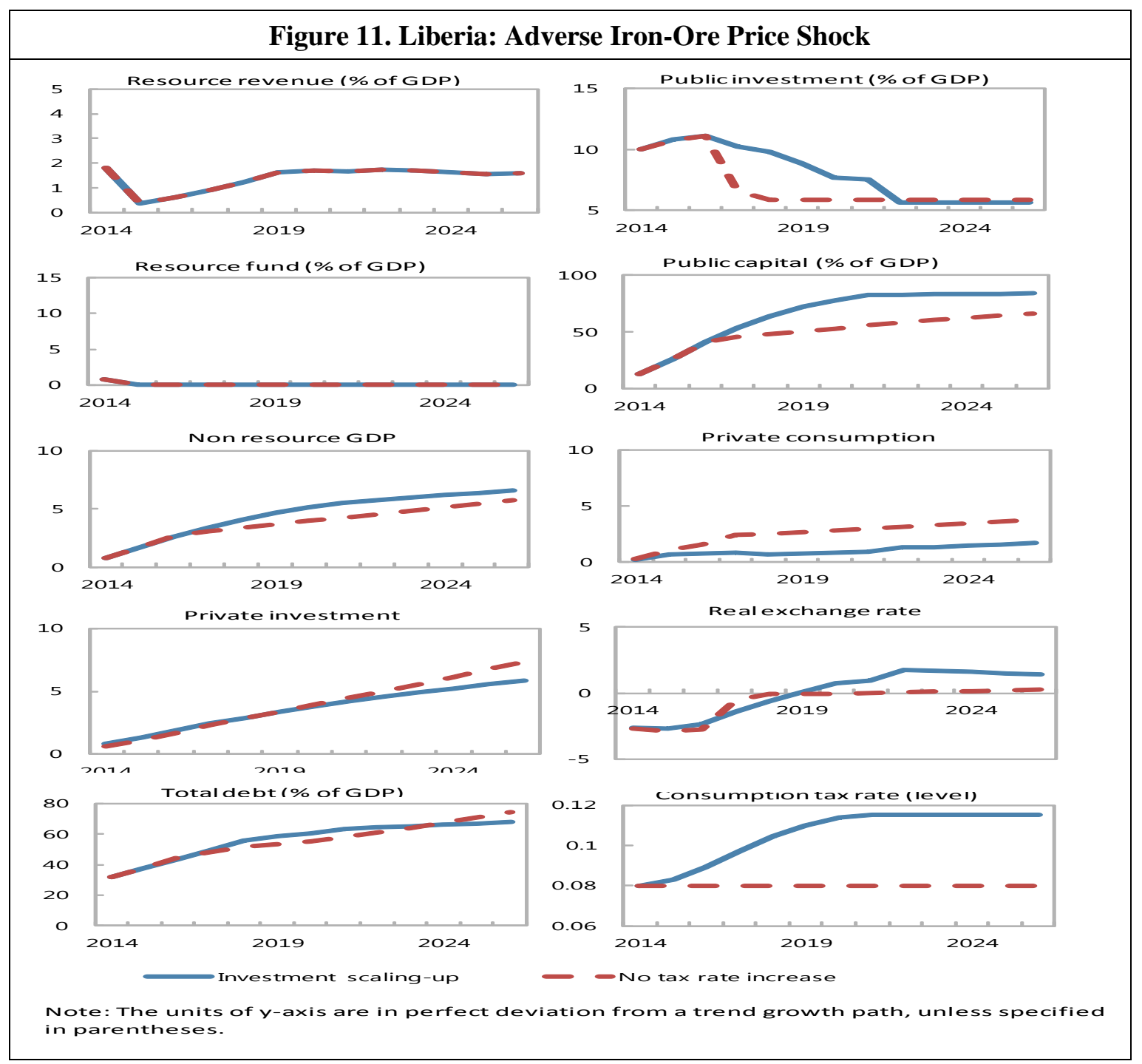

Under the adverse price shock and as compared to the baseline scenario, government debt increases more and consumption tax rates also have to be raised more to stabilize debt growth. As a result, private consumption does not rise as much in the adverse scenario. If there is a binding institutional constraint on fiscal adjustment, public investment has to be cut starting 2017 in order to maintain debt sustainability.

Note that private investment and consumption perform better relative to the approach with fiscal adjustments despite a lower buildup of public capital. The simulations without the fiscal adjustments assume that consumption tax rates are higher beyond the simulation horizon, but only in order for a rational expectation solution to be found. Better consumption and investment performances are driven by lower consumption tax rates conditional on household expectations that government remains solvent by implementing fiscal adjustments later.

Côte d'Ivoire. Appendix 3, Figure 1 presents the responses with the four fiscal approaches for Côte d'Ivoire. Côte d'Ivoire is the only country among the four for which the main resource commodity is oil (rather than mining). Given that oil production often faces less uncertainty 
beyond the initial exploration stage (International Monetary Fund, 2012); the revenue difference between the baseline and optimistic scenarios is small relative to the other three countries.

Non-resource revenues are important for investment scaling-up in Côte d'Ivoire. In both the baseline and optimistic scenarios, resource revenues are only a small part of government income. Except for the investment path under the PIH rule, other scaling-up approaches require a substantial increase in borrowing and, therefore, ultimately in consumption tax revenues to face a higher debt service. Even when the consumption tax rate is raised by 3 percentage points, total debt climbs to almost 80 percent of GDP in 2026. When the increase in the consumption tax rate is not feasible, it would require public debt to climb to over 100 percent of GDP. Both debt levels may be considered as excessive and may imply that investment scaling-up in Côte d'Ivoire should remain prudent.

While even a moderate scaling-up implies some debt sustainability issues, investing at 2-3 percent of GDP, as implied under the PIH rule, leads to little growth in non-resource GDP and private consumption. Striking a balance between the constantly high and low investment levels is important to deliver some growth benefits from investing resource revenues while maintaining debt sustainability.

Guinea. Appendix 3, Figure 2 presents the simulation results for Guinea under the two major scaling-up paths: one implied by NRB rule (blue solid lines) and one with slightly reduced investment scaling-up but higher transfers (red dashed lines). The approach without fiscal adjustments is also simulated to see its consequence on debt sustainability.

High uncertainty surrounds resource revenue projections for Guinea. Under the baseline scenario, resource revenues are only 2-4 percent of GDP, while under the optimistic scenario, resource revenues jump to 17-19 percent of GDP starting 2022. If the expected increase in resource revenues does not materialize as shown in the baseline scenario and consumption tax rates cannot increase to stabilize debt growth, public debt would become unsustainable, approaching 100 percent of GDP in 2026 (green dotted lines). International Monetary Fund (2012) emphasizes the risks of mining in the development and extraction phases. When planning an investment scaling-up conditional on expecting future mining revenues, it is important to consider the production quantity uncertainty and feasibility of alternative nonresource revenues.

Sierra Leone. Appendix 3, Figure 3 presents the simulation results for Sierra Leone under the same three fiscal approaches used by Guinea. Under the baseline scenario, the very low level of resource revenues (around 1 percent of GDP) requires a substantial increase in additional borrowing to support a constant investment spending level at almost 8 percent of GDP. If the consumption tax rates cannot increase to stabilize debt growth, government debt would continue to rise, reaching almost 60 percent of GDP in 2026. On the other hand, the optimistic scenario projects that resource revenue would increase to over 6 percent of GDP after 2022. 
When consumption tax rates can increase, government debt remains manageable. However, if this fiscal adjustment is not feasible, government debt rises to 60 percent of GDP in 2026.

\section{General Lessons}

There is a trade-off between scaling up public investment and debt sustainability. Harnessing natural resource wealth is an opportunity for these four fragile states to close a sizeable development gap. Increasing the stock of productive public capital boosts non-resource GDP growth and fuels private investment. However, investment plans should be mindful of the high uncertainty of future resource revenue, which would remain quite small in the baseline scenario, so that some amount of borrowing would be required. Depending on the size of the scaling up and the increase in borrowing, there is a risk of unsustainable debt accumulation.

Debt sustainability becomes a larger risk when fiscal adjustments are difficult to implement. For fragile states, even a modest increase in tax collection can be logistically demanding and politically fraught. The debt sustainability issues involved in a scaling-up can be exacerbated by the inability to adjust fiscal policy. Even under our baseline investment simulations, results suggest that countries run into debt sustainability problems by failing to raise tax rates.

Fiscal adjustment comes at a cost to private consumption. When the government increases the tax rate on consumption to cover the cost of borrowing, private consumption contracts. This can offset the gains to non-resource GDP made by the buildup of public capital. If the fiscal adjustment is especially severe, it is possible for private consumption to fall relative to its baseline level, despite the buildup of public capital. When fiscal adjustment is politically difficult, then a less aggressive, more gradual scaling-up strategy would be more suitable.

Scaling up public investment too quickly can lead to binding absorptive capacity constraints (Warner, 2014). These constraints can be especially binding in fragile post-conflict states where there is little institutional knowledge of managing large-scale investment projects. In the set of optimistic resource revenue scenarios, the additional fiscal space is spent on additional investment projects, but this comes at the cost of lower investment efficiency. The net result is a negligible increase in the stock of public capital relative to a more modest investment strategy. For MRU countries, "investing in investment" to raise investment efficiency would bring significant returns.

Negative price (or other) shocks can have significant consequences for debt sustainability. Given the volatile nature of natural resource prices, it is necessary to consider the downside risks of large scaling up strategies under price uncertainty. Even a limited scaling up can lead to unsustainable debt dynamics in the event of a negative price shock as shown in the Liberia simulation. This risk is particularly heightened for fragile post-conflict states that are constrained in their ability to adjust tax rates, and highlights the importance of avoiding too large up-front borrowing in anticipation of future resource windfalls.

The current fiscal strategy in the MRU countries, focused on gradual scaling up of public investment to spur sustained economic growth, appears broadly appropriate given the limited fiscal space and absorptive capacity. However, further increases in investment will be necessary to overcome infrastructure bottlenecks. Achieving this objective while preserving 
debt sustainability will require that this strategy be coupled with structural reforms to increase the efficiency of public investment and absorptive capacity, boost non-resource revenue collection and improve the business climate to crowd in private sector. The Ebola outbreak has also highlighted that, whereas closing infrastructure gaps is important, the costs of neglecting social spending, in this case on health and social protection, can be quite high.

\section{Allocating Part of Resource Wealth to Social Protection}

Simulation results from the DIGNAR model show that direct transfers to households have an immediate benefit in raising private consumption (see Figure 9). Given the large share of handto-mouth households in these four countries, cash transfers provide a direct boost to private consumption. This can offset the decline in private consumption caused by a fiscal adjustment and make that adjustment politically palatable. While outside the scope of the DIGNAR model, direct cash transfers can also aid social cohesion and political stability in the face of large natural resource discoveries, both crucial in post-conflict fragile states (Collier et al. 2010). Beyond these positive macroeconomic effects, the question for MRU countries is how to effectively implement the increase in transfers, given weak administrative capacity and the very limited existing social safety net systems (described in Appendix I).

As laid out in Gupta et al. (2014), in poor countries there is a case for earmarking part of natural resource revenue to cash transfers, as it would help enhance transparency and accountability and ensure their sustainability. Sala-i-Martin and Subramanian (2012) similarly suggest direct distribution of resource revenues can avoid the waste and weak institutional structure of public spending. However, direct redistribution of natural resource revenue in the form of a citizens' dividend, as implemented in Alaska and Alberta, would likely be problematic where institutional capacity is weak and there are no adequate distribution and monitoring mechanisms. Moreover, it has been shown that transfers that target the poorest and the most vulnerable can much more effectively reduce or eliminate the poverty gap (Monchuk, 2014). Using a small portion of natural resource revenue could help gradually and sustainably expanding social protection systems to reduce extreme poverty and maintain social cohesion.

In the last decade - excluding most recent periods of turmoil in Guinea, and Cote d'Ivoire - the MRU countries have taken measures to improve the quality of policy implementation to support growth and put in place some social safety nets (SSN) programs to address the needs of the most vulnerable groups in the population. This, combined with increased pro-poor spending has translated in some improvements in social indicators. Nonetheless, given limited fiscal space and administrative capacity, social protection systems are embryonic, fragmented, and financed by various donors. Total spending on social safety nets amounts to $3 \frac{1}{2}$ percent of GDP in Sierra Leone and 11/2 percent of GDP in Liberia (Monchuk, 2014), with the lion's share of spending on transfers going to food distribution, public work programs and health and education fee waivers.

A growing literature discusses the experience and prospects for enhancing safety nets in sub-Saharan Africa (Box 3). The main lessons from these reviews and recommendations for the MRU countries can be summarized as follows: 
- Design a medium-term national social protection strategy. The strategy would be embedded in each country's development plan, and assign clear institutional responsibilities and define coordination mechanisms. The strategy would aim at integrating the most successful existing interventions and ensure coordination with donors.

\section{Box 3. The Recent Experience with Social Protection Systems}

A large body of literature and empirical evidence show that social protection (SP) is critical for poverty reduction and inclusive growth. Although there is not a single definition, it is generally agreed that SP interventions typically include: (a) social assistance programs, such as cash or in kind transfers to alleviate poverty, often termed social safety nets ( $\mathrm{SSN}$ ); (b) social insurance programs, such as contributory programs, (i.e., pensions, unemployment benefits and health insurance); and (c) passive labor regulations and active labor market programs, such as education and training, credit, and employment services (Holzmann and Jorgensen, 2000).

Social protection systems vary greatly depending on countries' institutional development and administrative capacity. In fragile and post-conflict countries interventions consist mainly of donorprovided safety nets in the context of humanitarian interventions. In OECD economies, social protection systems are primarily insurance-based, linked to formal labor markets, and financed domestically through tax bases (Gentilini and Omamo, 2009).

Social safety nets are thus the most prevalent form of social protection in sub-Saharan Africa (Monchuk, 2014, Garcia and Moore, 2012). The most common forms of safety nets are school feeding programs, public works programs, in-kind emergency and non emergency programs, transfer programs and general subsidies are the most common, with very few cash transfer programs. Spending on social safety nets in Africa averages about 1.7 percent of GDP and 4.4 percent of government spending, with donors being the main financiers (excluding general subsidies). The evidence to date suggests that social safety nets have a positive long-term impact on the poorest households, allowing them to invest more in health and education.

The experience with conditional cash transfers, whereby the cash transfer is conditioned on investments in human capital, such as sending children to school or health clinic attendance, suggests that these have been effective at reducing income inequality and poverty in Latin America (Lustig et al., 2013). However, these programs require the availability of detailed household information and fairly developed administrative systems to effectively target those in need, deliver the benefits and monitor the programs. In sub-Saharan Africa both data availability and capacity are quite limited, though some pilot conditional cash transfers are showing positive results. Nonetheless, an evaluation of a small pilot conditional cash transfer program in Liberia suggests that it may have increased school enrollment, food security, improved child and adult health, and boosted the local economy. Challenges ranged from misuse of transfers to difficulties in targeting, monitoring impact due to lack of data.

- Develop a few key safety net programs based on a careful analysis of the countries' needs, while building institutional and administrative capacity. Given institutional and administrative limitations in the MRU country, in the beginning priority could be given to selecting a few cash transfer programs that have proven effective targeting the most vulnerable households, and expanding them. While such programs would be countryspecific, the following aspects would need to be considered: (i) effective targeting based on poverty maps and households surveys; (ii) improved coverage and increased coordination among providers; (iii) enhanced institutional and administrative arrangements, particularly for the selection and registration of beneficiaries and payment systems; and (iv) efficient monitoring mechanisms to ensure the highest impact. Specific options could include 
seasonal public work programs to help with the building of rural roads or other infrastructure; vouchers programs; non-conditional cash transfers targeting the elderly, school-age children, food insecure populations. Labor policies and insurance schemes could also be strengthened by allocating a portion of cash transfers to non-contributory pension schemes to targeted groups of vulnerable elderly, notably disabled war victims and jobless adults with disability.

\section{CONCLUSION}

Tapping the natural resource potential of fragile countries does hold great promise in unlocking fiscal space to address infrastructure gaps and promote inclusive growth. Recognizing the limits of authorities' or staff's ability to project resource revenue, as well as realizing that, perhaps with the exception of Guinea, resource revenue in MRU countries is likely to remain limited in the foreseeable future, this study has sought to highlight key elements to consider before considering significant scaling-up of public investment. First, sound fiscal regimes and effective and transparent natural resource administration are essential for maximizing government revenue over project life (IMF, 2012b). Second, for MRU countries, we show that simple fiscal rules based on a sustainable non-resource deficit can be robust to fairly high resource revenue uncertainty. Third, model results highlight the merits of a sustainable public investment scaling up strategy, particularly when tax increases are politically unpalatable and access to commercial borrowing is limited. Finally, higher resource revenue can help the MRU countries scale-up social protection programs and reduce extreme poverty.

While all the above general conclusions apply to a broader group of resource-rich developing countries, they are even more relevant for fragile countries in general and MRU countries in particular, characterized as they are by weaker capacity to assess and project natural resource revenue, implement complex fiscal rules, and mitigate external shocks. These considerations would warrant even more conservative investment scaling up plans in order to maintain some level of precautionary buffers going forward.

The current Ebola epidemic that is affecting the three poorest MRU countries also sadly illustrates how elusive projections of natural resource revenue can be. Although it is premature to fully assess the full extent of the Ebola outbreak's economic impact, as all indications point to significant reductions in current production, at least in Liberia and Sierra Leone, and to delays in future mining investment in all three countries. This in turn will contribute to push even further into the future the point where resource revenue could become significant. Additional donor support can help cover a good part of the additional spending needs associated with containing the outbreak in the short term, and rebuilding health systems and safety nets in the medium term. However, additional spending demands will further contribute to compress already paltry budget envelopes. In this context, starting to save even some nominal amount of natural resource revenue early on might be a useful way to build a buffer against external shocks and create an early constituency for sound natural resource management. The severe impact of the epidemic on the poor and vulnerable groups also highlights the importance of establishing nation-wide social safety nets that can be scaled up in case of emergencies. 


\section{References}

Ardic, O.P., K. Imboden, and A. Latortue, 2013, "Financial Access 2012”, Consultative Group to Assist the Poor and International Finance Corporation, World Bank Group, Washington, D.C.

Arestoff, F. and C. Hurlin, 2006, "Estimates of Government Net Capital Stocks for 26 Developing Countries, 1970-2002." World Bank Policy Research Working Paper 3858, Washington, D.C.

Barnett, S., and R. Ossowski, 2003, "Operational Aspects of Fiscal Policy in Oil-Producing Countries," in Fiscal Policy Formulation and Implementation in Oil-Producing Countries, ed. by J. Davis, R. Ossowski, and A. Fedelino.

Baunsgaard, T., M. Villafuerte, M. Poplawski-Ribeiro, and C. Richmond, "Fiscal Frameworks for Resource-Rich Developing Countries", IMF Staff Discussion Note 12/04, International Monetary Fund, Washington, D.C.

Berg, A., J. Gottschalk, R. Portillo, and L.F. Zanna, 2010. "The Macroeconomics of Mediumterm Aid Scaling-up Scenarios.” IMF Working Paper 10/160, International Washington Fund, Washington, D.C.

Berg, A., R. Portillo, S.-C. S. Yang, L.-F. Zanna, 2013, "Public Investment in ResourceAbundant Developing Countries,” IMF Economic Review, 61(1), 92-129.

Buffie, E. F., A. Berg, C. Pattillo, R. Portillo, and L.-F. Zanna, 2012, "Public Investment, Growth, and Debt Sustainability: Putting together the Pieces," IMF Working Paper 12/144, International Monetary Fund, Washington, D.C.

Collier, P., R. Van der Ploeg, M. Spence, and A. Venables, 2010, "Managing Resource Revenues in Developing Economies”, IMF Staff Papers, Vol. 57, No.1, pp. 84-118.

Dabla-Norris, E., J. Brumby, A. Kyobe, Z. Mills, and C. Papageorgiou, 2011. "Investing in Public Investment: An Index of Public Investment Efficiency." IMF Working Paper 11/37, International Monetary Fund, Washington, D.C.

Davis, J., J. Ossowski, J. Daniel, and S. Barnett, 2001, "Stabilizing and Saving Funds for Nonrenewable Resources: Experience and Fiscal Policy Implications, "IMF Occasional Paper No. 25, International Monetary Fund, Washington, D.C.

Fox, L., C. Haines, J. Huerta Muñoz, and A. Thomas, 2013, “Africa's Got Work to Do”, IMF Working Paper 13/201, International Monetary Fund, Washington, D.C.

Garcia and Moore, 2012 "The Cash Dividend, the Rise of Cash Transfer Programs in Sub-Saharan Africa". Directions in Development, Human Development, World Bank, Washington D.C. 
Gelb, A. H., 1988, Oil Windfalls: Blessing or Curse, Oxford, UK: Oxford University Press.

Gentilini, U., and S. Were Omamo, 2009, "Unveiling Social Safety Nets”, Occasional Paper No. 20, World Food Program.

Gros, D., T. Mayer, 2012, “A sovereign wealth fund to lift Germany’s curse of excess savings. CEPS Policy Brief No. 280, August 28, Centre for European Policy Studies.

Gupta, S., A. Kangur, C. Papageorgiou, and A. Wane, 2014, "Efficiency-Adjusted Public Capital and Growth," World Development, 57, 164-178.

Gupta, S., A. Segura-Ubiergo, and E. Flores, 2012, "Direct Distribution of Resource Revenues: Worth Considering?" Staff Discussion Note 14/05, International Monetary Fund, Washington, D.C.

Holzmann, R., and S. Jorgensen, 1999. "Social Protection As Social Risk Management: Conceptual Underpinnings for the Social Protection Sector Strategy Paper," Social Protection Discussion Papers 20119, The World Bank, Washington, D.C.

Horvath, M., 2000. "Sectoral shocks and aggregate fluctuations," Journal of Monetary Economics 45 (1), 69-106.

International Bank for Reconstruction and Development/World Bank, 2010, Cost-Benefit Analysis in World Bank Projects. The International Bank for Reconstruction and Development/The World Bank, Washington, D.C.

International Monetary Fund, 2009, “The Fund's Facilities and Financing Framework for LowIncome Countries," SM/09/55, SM/09/55 Supplement 1, SM/09/55 Supplement 2, International Monetary Fund, Washington, D.C.

International Monetary Fund, 2012a, Macroeconomic Frameworks for Resource-Rich Developing Countries, Washington, D.C.

International Monetary Fund, 2012b, Fiscal Regimes for Extractive Industries: Design and Implementation, Washington, D.C.

International Monetary Fund, 2014, "Chad-2013 Article IV Consultation and Assessment of Performance under the Staff-Monitored Program — Staff Report," IMF Country Report No. 14/100, Washington D.C.

International Monetary Fund, 2014, Fiscal Policy and Income Inequality, Washington D.C.

Lustig et al., 2013, “The Impact of Taxes and Social Spending on Inequality and Poverty in Argentina, Bolivia, Brazil, Mexico, Peru and Uruguay: An Overview”, CEQ Working Paper No. 13, August. 
Melina, G., S.-C. S. Yang, and L.-F. Zanna, 2014, "Debt Sustainability, Public Investment, and Natural Resources in Developing Countries: the DIGNAR Model," IMF Working Paper 14/50, International Monetary Fund, Washington, D.C.

Melina, G., and Y. Xiong, 2013, "Natural Gas, Public Investment and Debt Sustainability in Mozambique," IMF Working Paper No. 13/261.

Monchuk, Victoria, 2014, "Reducing Poverty and Investing in People, the New Role of Safety Nets in Africa", The World Bank, Washington D.C.

Minasyan, G. and Yang, S.C. S., 2013, "Leveraging Oil Wealth for Development in Kazakhstan: Opportunities and Challenges," Selected Issues, IMF Country Report No. 13/291, International Monetary Fund, Washington, D.C.

Ogaki, M., J. Ostry, and C. Reinhart, 1996, "Saving behavior in low- and middle-income developing countries: A comparison,” IMF Staff Papers 43 (1), 38-71.

Sachs, J. D. and A. M. Warner, 1999, "The Big Push, Natural Resource Booms and Growth," Journal of Development Economics, Vol. 59, No. 1, pp. 43-76.

Sachs, J. D. and A. M. Warner, 2001, "The Curse of Natural Resources," European Economic Review, Vol. 45, No. 4-6, pp. 827-838.

Sala-i-Marin, X. and A. Subramanian, 2012, "Addressing the Natural Resource Curse: An Illustration from Nigeria," Journal of African Economics, Vol. 22, No. 4, pp. 570-615.

Ugo, G. and S.W. Omamo, 2011, "Social Protection 2.0: Exploring Issues, Evidence and Debates in a Globalizing World" Elsevier, Food Policy 36, pp. 329-340.

Ugo, G. and S.W. Omamo, 2009, "Unveiling Social Safety Nets" World Food Programme, Occasional Paper No, 20; 23 pages.

Van der Ploeg, F., 2011, “Natural Resource: Curse or Blessing?” Journal of Economic Literature, 49(20) 366-420.

Van der Ploeg, F. and Venables, A., 2011, "Harnessing windfall revenues: Optimal policies for resource-rich developing economies", The Economic Journal Vol. 121, No. 551, pp. 1-30.

Van den Bremer, T. S. and Frederick van der Ploeg, 2013, "Managing and Harnessing Volatile Oil Windfalls," IMF Economic Review Vol. 61, No. 1, 130-167.

Van Wjinbergen, S., 1984, “The 'Dutch Disease': A Disease At All?” The Economic Journal, Vol. 94, pp. 41-55.

Warner, A., 2014, "Public Investment as an Engine of Growth", IMF Working Paper No $14 / 148$.

World Bank, 2013, Sierra Leone: Social Protection Assessment, Washington, DC. 


\section{Appendix 1. Poverty Diagnostics and Safety Nets in the MRU Countries}

\section{Côte d'Ivoire}

Poverty diagnostic. Poverty indicators have not been updated since 2008, but the authorities estimate that the displacements of population and the sharp deterioration of social services in most of the country during the crisis resulted in slightly more than half the population living below the poverty line in 2011, against 48 percent in 2008 and only 10 percent in 1985 . The real per capita income in 2011 was only about 57 percent of its peak 1978 level. Since the end of the post-election conflict in April 2011, high and broad-based average annual real GDP growth of about 9 percent in 2012-13 has most likely improved poverty indicators. Poverty is likely to decline following the adoption of the cocoa reform, the setting up of a minimum price for cotton and cashew and, more recently, an increase in the minimum wage, which may have an impact on lower wages. The government has boosted pro-poor spending from 7.4 to 9.3 percent of GDP in 2011-13, with priority to health and education, and is setting up a health insurance scheme.

Social safety nets. A few small SSN programs have been executed. These programs include a small cash transfer program to support the reinsertion of former soldiers, a few public-work programs aimed at unemployed youth and a WFP-run school-feeding program. Government spending on these programs is about 0.04 percent of GDP for targeted social spending and 0.23 percent of GDP if spending on former soldiers is included. The authorities, with the support of the World Bank, are preparing a comprehensive social safety net strategy that would include a cash-transfer program in poor rural areas and lay the foundations of a basic national safety net system. A universal health insurance program will begin operating in 2015.

\section{Guinea}

Poverty diagnostic. Two small-scale surveys for the evaluation of poverty (ELEP) carried out in 2007 and 2012 by the National Institute of Statistics point to a worsening of poverty, with poverty rates rising from 53 to 55.2 percent over 2007-12. This deterioration is the legacy of weak policies implemented under the 2009-10 military rule, and more marked in urban areas, where the poverty rate increased by 5 percentage points against 1.7 percentage points in rural areas. However, poverty rates remain higher in absolute terms in rural areas. In addition to the location, rising food prices — which accounts for over 30 percent of child malnutrition ratesgender and education of household heads were identified as the main determinants of poverty.

Social safety net. The only formal social safety net existing is the "Productive Social Safety Net Project" approved by the World Bank in May 2012. With a total cost of US\$25 million, fully financed by the World Bank over 2013-18, the main objective of the project is to provide income support to vulnerable groups and to lay the foundations of a SSN strategy by testing some of the building blocks necessary for a larger system. From a thematic standpoint, the project focuses on social safety nets (95 percent) and on labor markets improvement (5 percent). It covers three main components: (i) implementation of a labor intensive public works and life skills development in rural areas targeted at youth (US\$16.50 million);

(ii) piloting a cash transfer project to improve human capital in rural areas (US\$4.50 million); 
and (iii) strengthening the institutional capacity of the government to design and coordinate social safety net interventions (US\$4 million).

\section{Liberia}

Poverty diagnostic. The poverty analysis is informed by the 2008 Housing and Population Census that defines poverty based on the Unmet Basic Needs (UBN) approach and the asset deficiency approach. The UBN approach concluded that poverty was relatively higher in rural areas compared to urban areas. The Core Welfare Indicator Questionnaire (CWIQ) results indicate that poverty in Liberia declined from 64 percent (2007) to 56 percent (2010). The poorest households are those where the head is self-employed in agriculture, less educated, and young. About 80 percent of the labor force in vulnerable employment with limited incomegeneration opportunities, and 28 percent is vulnerable to food insecurity.

Social safety net. Social assistance programs focus on food security (76 percent of total spending), and public works program, targeting the food insecure and the unemployed or under-employed (about three quarters of the population). Estimates indicate that social safety nets interventions reached about 830,000 beneficiaries in 2010 , or about 24 percent of the population, (though coverage likely overestimated due to overlap of interventions). Total average benefits cover only between 7 and 20 percent of the poverty line. Social transfers are highly fragmented between uncoordinated, often small-scale interventions, and mostly donorfinanced ( 93.8 percent of the total). Nonetheless, the cash-for-work temporary employment projects in Liberia has shown positive benefits: created temporary employment for 17,000 vulnerable Liberians and transferred US\$2 million to these households with an average reduction in the poverty gap of 27 percent, from 17.2 percent to 12.6 percent.

\section{Sierra Leone}

Poverty diagnostic. An integrated household survey estimates that the national headcount poverty rate declined from 66.4 in 2003 to 52.9 percent in 2011 . The overall reduction was led by strong drop in rural areas, where headcount poverty declined from 78.7 to 66.1 percent; urban poverty declined from 46.9 to 31.2 percent; but increased in Freetown from 13.6 to 20.7 percent, due to economic migrants. The intensity of poverty has declined, helping to reduce the national poverty gap from 27 to 16.1 percent. Food poverty has decreased from 68.1 percent in 2003 to 47.7 percent in 2011 , led by moderation in urban areas. Survey data indicate that poverty incidence is highest among larger households ( $7+$ persons), and where the household head is elderly or employed in agriculture.

Social safety net. SSN programs have been executed through line ministries and government agencies involved in social and welfare issues; local authorities; Non Government Organizations (NGOs); and civil society and faith-based organizations. In the last five years, the main social safety nets programs included the following programs: (i) the Free Health Care Initiative (for pregnant women, lactating mothers, and children under 5 years of age); school feeding programs; cash transfers; cash-for-work; Food Security Project; Youth Employment Program and Youth Enterprise Development; and programs for the elderly. 


\section{Appendix 2. Fiscal Regimes and Resource Revenue Scenarios}

\section{A. Fiscal Regimes}

Côte d'Ivoire. For the oil fields, Côte d'Ivoire uses production-sharing agreements (PSAs) that give the government a share of the total oil production. Exploration and production rights, as well as the production-sharing modalities, are determined by contracts between the government, the private companies, and the public enterprise Petroci, which manages the government's share of oil production. There are no royalties, special company profit taxes, or other fees or levies. The new mining code, adopted in 2014, provides several tax incentives for titles holders including inter alia, VAT and customs relief for a broader range of imported goods, income tax exemption for the five first years such as property tax on specific land, water tax. It maintains the royalty system comprising taxes based both on surface rent and turnover of the project company. However, the rates of mining royalties are not specified in the new Code, but will be included in the Application Decrees. The new code provides for tax stability. Mining permits are subject to the grant of 10 percent free carried interest in favor the government in the share capital of the project company. In addition, the government may acquire up to 15 percent of the shares of the project company, the additional share being at market price.

Guinea. A new mining code was approved in April 2013, with a view to ensuring a larger share for the government. Mining companies are subject to a royalty ( 3 percent for iron-ore, 0.075 percent for bauxite) and to a production tax (between 2 and 5 percent for gold and diamond). A corporate income tax (35 percent) is also applied, but some tax holidays are often granted over a given period of time. Mining companies also have to pay an export tax, but, in return, are exempted from the value added tax (VAT) to ensure economic neutrality. The government has established a committee to review all the 18 existing mining titles and conventions to bring them in line with the new code. ${ }^{1}$ Contracts are published online and Guinea is expected to reach the validation point of the Extractive Industries Transparency Initiative (EITI) by April 2014.

Liberia. The current revenue code of November 2011 makes appropriate provisions for taxing large-scale mining activities and the governance of the mining sector seems appropriate, which could facilitate the government to collect a fair share of mining revenues on a transparent way. On a comparative basis, the Liberian mining fiscal regime is projected to raise revenues for the government similar to international benchmarks. Liberia is a member of the EITI and has made public the signed concession agreements, contributing to fostering transparency in the sector. However, existing concession agreements are not standard as they include ad-hoc fiscal terms negotiated prior to the current revenue code which may limit the government's potential fiscal

\footnotetext{
${ }^{1}$ The technical committee recently recommended the repealing of the BSGR-VALE concession agreement on the Northern bloc of the Simandou iron-ore deposit, which has been fully endorsed by the Government. But BSGR threatened to take the case to international courts, adding to the uncertainties surrounding the development of this mine.
} 
receipts. The mining fiscal regime comprises royalty, income tax, and surtax on income from high yield projects while the regime for the petroleum sector combines royalty-income tax with contractual terms under production sharing contract (PSC). Signed PSCs also include ad hoc fiscal terms. The government is currently working on passing a new petroleum law with a view to improving governance in the sector and updating the petroleum fiscal regime to international standards.

Sierra Leone. A tax and royalty regime applies to the mining industry. It is regulated by the Mines and Minerals Act 2009 (MMA) and the Income Tax Act 2000 (ITA) as amended up to 2010. The MMA cross-refers to ITA, so the ITA prevails on matters within its scope. The MMA provides for five classes of mineral license: reconnaissance, exploration, and then - for extraction - artisanal, small-scale, and large-scale. Each of the three extraction licenses is, in principal, subject to the same fiscal terms. Although neither MMA nor ITA contains specific provisions enabling the making of special agreements revising fiscal terms for mining projects, the legislated general regime has been overridden in five cases by special agreements given the force of law after ratification in Parliament. These special agreements provide assurance to the investor as it is a contract containing binding provisions. If the government amends the terms unilaterally, it runs the risk of litigation. The prevailing special agreements differ from investor to investor, variously providing fiscal concessions relative to MMA terms on corporate income tax, dividend withholding tax and import duties, and/or reduced tax rates for royalty.

\begin{tabular}{|c|c|c|c|c|}
\hline \multicolumn{5}{|c|}{ Table 1. Fiscal Regime in the MRU Countries } \\
\hline \multicolumn{5}{|c|}{ Mining Regime } \\
\hline & Liberia & Guinea & Sierra Leone & Côte d'Ivoire \\
\hline Royalty & $3 \%-5 \%$ & $2 \%-10 \%$ & $3 \%-5 \%$ & $3 \%$ \\
\hline Corporate Income Tax & $30 \%$ & $35 \%$ & $37.5 \%$ & $35 \%$ \\
\hline State Participation & Varies & Varies & Varies & $10 \%$ \\
\hline Additional Benefits Tax & NA & $50 \%$ & NA & Accelerated \\
\hline Depreciation & $2.5 \%-30 \%$ & $20 \%-33 \%$ & $20 \%-100 \%$ & NA \\
\hline Loss Carry Forward & 5 yrs. & 3 yrs. & Indefinitely & NA \\
\hline \multicolumn{5}{|l|}{ Withholding Taxes } \\
\hline On Dividends & $15 \%$ & $15 \%$ & $10 \%$ & $12 \%$ \\
\hline On Interest & - & $20 \%$ & $15 \%$ & $18 \%$ \\
\hline On interest to non residents & $30 \%$ & $20 \%$ & $0 \%$ & $18 \%$ \\
\hline On Royalties & - & - & - & - \\
\hline On royalties to non residents & $30 \%$ & $10 \%$ & $25 \%$ & $20 \%$ \\
\hline Capital Gains Tax & & & & $20 \%$ \\
\hline \multicolumn{5}{|c|}{ Petroleum Regime } \\
\hline & Liberia & Guinea & Sierra Leone & Côte d'Ivoire \\
\hline Signature Bonus & Varies & - & - & $\$ 300,000$ \\
\hline Production Bonus & - & - & - & $\begin{array}{l}\text { US\$1 M- } \\
\text { US\$10 M }\end{array}$ \\
\hline
\end{tabular}




\begin{tabular}{|l|c|c|c|c|}
\hline Royalty & Liberia & Guinea & Sierra Leone & Côte d'Ivoire \\
\hline Oil offshore & $12 \%-15 \%$ & $10 \%$ & $10 \%, 6.5 \%, 8 \%$ & - \\
\hline Gas & $12 \%-15 \%$ & $10 \%$ & - & - \\
\hline Cost Recovery Limit & $70 \%$ & $75 \%$ & NA & $40 \%$ \\
\hline Production Sharing & $40 \%-60 \%$ & $20 \%-60 \%$ & NA & $60 \%-90 \%$ \\
\hline Corporate Income Tax & $35 \%$ & $35 \%$ & $30 \%, 37.5 \%$ & - \\
\hline State Participation & $20 \%$ & $15 \%$ & NA & $10 \%$ \\
\hline Depreciation & $\begin{array}{c}\text { Defined in } \\
\text { contract }\end{array}$ & $5 \%-33 \%$ & $20 \%-100 \%$ & $\begin{array}{c}\text { Defined in } \\
\text { contract }\end{array}$ \\
\hline Investment Allowance & NA & NA & $20 \%-100 \%$ & NA \\
\hline Loss Carry Forward & 5 yrs. & 3 yrs. & Indefinitely & 5 yrs. \\
\hline Withholding Taxes & \multicolumn{5}{|l|}{} \\
\hline On Dividends & Exempt & $20 \%$ & $0 \%$ & $10 \%, 12 \%$ \\
\hline On Interest & Exempt & $20 \%$ & $10 \%$ & $15 \%$ \\
\hline On interest to non residents & Exempt & $20 \%$ & $10 \%$ & $15 \%$ \\
\hline On Royalties & Exempt & - & $25 \%$ & $27 \%$ \\
\hline On royalties to non residents & Exempt & $10 \%$ & $25 \%$ & $27 \%$ \\
\hline
\end{tabular}

\section{B. Resource Revenue Scenarios}

\section{Côte d'Ivoire}

The baseline scenario assumes a gradual increase in the oil and natural gas production, as technical problems on the existing fields are fixed, and new discoveries are developed particularly in the area which constitutes Côte d'Ivoire's maritime border with Ghana, where the oil prospects are important. In this regard, crude oil is assumed to reach 193,000 barrels per day by 2026 from 25,000 barrels per day in 2013, and remain flat thereafter. ${ }^{2}$ On the natural gas segment, the production would increase from about 75,000 million BTU in 2013 to 110 , 000 million BTU by 2024, remaining flat thereafter. As a result, oil revenue is expected to increase from 1 percent of GDP (5.4 percent of total revenue) in 2013 to about 2.8 percent of GDP (9.9 percent of total revenue) by 2026 , before declining gradually to 1.9 percent of GDP (6.2 percent of total revenue).

The optimistic scenario includes only oil and natural gas. ${ }^{3}$ It assumes a higher increase in oil and natural gas production. In this scenario, crude oil production would reach about 200000 barrels per day by 2020 and 250000 barrels per day by 2028. The production of natural gas

\footnotetext{
${ }^{2}$ The authorities' projections are more ambitious, with oil production expected at 200,000 barrels per day within five years.

${ }^{3}$ Little information is available on the large iron-ore project as well as bauxite and other minerals. The direct revenue impact of gold projects is negligible at about 0.03 percent of GDP per year. Data availability issues and considerable uncertainty on the profile of investment have not allowed to include a surge in mining activities in the scenario.
} 
would increase over time, reaching 200,000 million BTU by 2025 and 340,000 million BTU by 2030. The petroleum revenue is expected to reach about 3.9 percent of GDP (16.8 percent of total revenue) by 2020, and to average 3.5 percent of GDP (12.8 percent of total revenue) over the rest of the period.

\section{Guinea}

The baseline scenario is basically made up of two phases. A first stage, spanning from 2014 to 2016, in which the mining activity consists of existing gold, bauxite and diamond extraction, representing respectively 50 percent, 33 percent and five percent of the country's total exports. The second stage covers 2017 onwards, with the bulk of the mining sector hinging on the large-scale Rio Tinto-led Simandou iron-ore project. This latter, with investments amounting to around US\$20 billion or three times Guinea's current GDP, is expected to start in $2017,{ }^{4}$ and will stand for roughly 50 percent of the country's total exports, reaching gradually almost 80 percent from 2020 onwards. Mining revenue will increase gradually from 2.8 percent of GDP in 2014 to 3.9 percent of GDP in 2020, standing for roughly 24 percent of total government revenue, compared to around 15 percent in 2014.

The optimistic scenario might be much rosier should the following projects come on stream: (i) expansion of the production capacity of the largest bauxite company (CBG) in two stages (an initial increase of 9 million of tons by 2017 and a further increase of 5 millions of tons by 2022). The needed investment for this extension amounts to US\$1 billion; (ii) A US $\$ 6$ billion investment from China Power Investment (CPI) to extract bauxite and to build an alumina refinery in Guinea. With the construction work expected to start in 2014, CPI is planning to produce 4 million tons of alumina during the first stage, which will be doubled in the second stage; (iii) A recently signed agreement with the United Arab Emirates for a $\$ 5$ billion investment project in the bauxite sector; and (iv) a potential US\$4 billion investment by a Russian company COBAD S.A. is expected to start in 2014 for an estimated production of 9 million of tons of bauxite a year (with a possible further increase to 12 million of tons).

\section{Liberia}

The baseline scenario reflects the activity of the two mining projects already under operation (i.e., Arcelor-Mittal and China Union). Production from the other three projects has not been included in the baseline given the limited information about their cost structure and production schedule. Under the baseline scenario, exports of iron-ore are expected to exceed 50 percent of total exports by 2017, and the government's revenue take is expected to increase slightly from about 2 percent of GDP in FY2013 to a 2.3 percent annual average over the medium to longterm reflecting the two-phase operation approach followed by the two companies. At full capacity, the combined production and exports of iron-ore from the two companies are expected to reach 20 million metric tons annually starting in 2021. The estimated government revenues include royalties and withholding taxes on subcontractors. Corporate income tax is

\footnotetext{
${ }^{4}$ Note that this starting date may switch to 2018 , as discussions on finalizing the legal investment framework have incurred some delays.
} 
projected to start flowing only after 2020 given the loss-carry-forward provisions in the revenue code. A strong oversight on the concessionaires will be critical to ensure the government effectively collects its share of revenues, particularly by reducing the risks of transfer price practices.

The optimistic scenario includes the coming on stream of two additional large iron-ore projects. One of them, Western Cluster, is already under construction with production expected to commence by 2015. A second major project, Putu, may come on stream by 2018. Once production from these two projects, at an estimated annual average of 27 million metric tons per year, is included, government revenues from iron-ore production as a share of GDP could reach 5.2 percent of GDP by 2021 up from around 2.2 percent of GDP in the baseline scenario. Iron-ore related revenues as a share of total revenues could represent up to close to 22 percent compared to less than 11 percent in the baseline.

\section{Sierra Leone}

The baseline projections assume that only implementation of Phase I of iron-ore ongoing projects takes place. Fiscal revenue comes only from royalty, as realization of corporate income tax (among other taxes) is contingent upon the timeline for project profitability and the speed and scale of further project expansion. Under the baseline scenario, Iron-ore exports are expected to decrease gradually from 55 percent of total exports in 2014 to less than 50 percent over the medium-term.

The optimistic scenario for iron-ore production includes full expansion to maximum potential of the two already existing mines (African Minerals Limited and London Mining) and the start of a mine for which an operating license is pending (Cape Lambert Resources). This optimistic outlook warrants some caution given that the outlook for future expansion is contingent on evolving capital investment requirements and uncertain market conditions. The scenario applies previously announced company guidance, although conservatively builds in additional delays on the ramping up profile. The optimistic scenario excludes a project announced by China Kingho, for which there are insufficient details. Under this scenario, peak iron-ore production would be achieved around 2022 at around 60 million tons p.a. sustained through the early 2030s, roughly 120 percent higher than the baseline scenario. Tax revenue associated with iron-ore would initially be around 50-60 percent higher than the baseline before 2020 due to royalties increasing with production. Thereafter, the optimistic scenario significantly diverges from the baseline, as revenues increase 3 fold through 2025 due to projected dividend withholding taxes, then briefly increase tenfold in 2025-28 from corporate income tax. Under the optimistic scenario, it is assumed that additional future revenue would allow for higher public investment in the medium term (2015-19), which increases by an average 1.7 percent of projected GDP financed through external non-concessional borrowing. 


\section{Appendix 3. Model Specification, Solution Method, Calibration, and Simulation Results}

The model description follows Melina et al. (2014) closely. The main differences from the original DIGNAR model are in the fiscal specification for managing resource revenues and the time-varying resource tax rates to target the resource revenues as a share of GDP, generated from the FARI model. Sections A to D specify the model, and Section E describes the equilibrium system, the solution method, and calibration.

\section{A. Households}

A fraction $\omega$ of the households have access to capital markets, where they can trade contingent securities and own firms (often referred as optimizing or Ricardian households). The remaining fraction 1- $\omega$ are financially constrained (also referred as hand-to-mouth or hand-to-mouth), who do not have access to capital and financial markets and consume all of the disposable income each period.

Let $O P T$ denote optimizing households and $H T M$ denote hand-to-mouth households. Both types consume a consumption basket, $c_{t}^{i}$, a constant-elasticity-of-substitution (CES) aggregate of traded goods $c_{T, t}^{i}$ and nontraded goods $c_{N, t}^{i}$. Thus, the consumption basket is

$$
c_{t}^{i}=\left[\varphi^{\frac{1}{x}}\left(c_{N, t}^{i}\right)^{\frac{\chi-1}{\chi}}+(1-\varphi)^{\frac{1}{x}}\left(c_{T, t}^{i}\right)^{\frac{\chi-1}{x}}\right]^{\frac{\chi}{x-1}}, \quad i=O P T, H T M
$$

where $\varphi$ is the degree of home bias in the consumption basket, and $\chi>0$ is the intra-temporal elasticity of substitution.

Let $p_{N, t}$ and $s_{t}$ be the relative prices of nontraded and traded goods to the consumption basket. Assume the law of one price holds for traded goods, $s_{t}$ is also the real exchange rate, defined as the price of one unit of foreign consumption basket in units of domestic basket. The unit price of the consumption basket is

$$
1=\left[\varphi p_{N}^{1-\chi}+(1-\varphi) s_{t}^{1-\chi}\right]^{\frac{1}{1-\chi}} .
$$

Both types of households provide labor service $\left(L_{T, t}^{i}\right.$ and $\left.L_{N, t}^{i}, i=O P T, H T M\right)$ to the traded and the nontraded good sectors, denoted by subscripts $T$ and $N$. Total labor $L_{t}^{i}$ has a CES specification to capture that labor supplied to the two sectors are not perfect substitutes,

$$
L_{t}^{i}=\left[\delta^{-\frac{1}{\rho}}\left(L_{N, t}^{i}\right)^{\frac{1+\rho}{\rho}}+(1-\delta)^{-\frac{1}{\rho}}\left(L_{T, t}^{i}\right)^{\frac{1+\rho}{\rho}}\right]^{\frac{\rho}{1+\rho}}, \quad i=O P T, H T M,
$$

where $\delta$ is the steady-state share of labor in the nontraded good sector, and $\rho>0$ is the intratemporal elasticity of substitution. Let $w_{T, t}$ and $w_{N, t}$ be the real wage rate paid in each sector. The real wage index is

$$
w_{t}=\left[\delta w_{N, t}^{1+\rho}+(1-\delta) w_{T, t}^{1+\rho}\right]^{\frac{1}{1+\rho}}
$$


A.1. Optimizing households. A representative optimizing household maximizes its utility

$$
E_{0} \sum_{t=0}^{\infty} \beta^{t} U\left(c_{t}^{O P T}, L_{t}^{O P T}\right)=E_{0}\left\{\sum_{t=0}^{\infty} \beta^{t}\left[\frac{1}{1-\sigma}\left(c_{t}^{O P T}\right)^{1-\sigma}-\frac{\kappa^{O P T}}{1+\psi}\left(L_{t}^{O P T}\right)^{1+\psi}\right]\right\},
$$

subject to the budget constraint,

$$
\begin{aligned}
& \left(1+\tau_{t}^{C}\right) c_{t}^{O P T}+b_{t}^{O P T}-s_{t} b_{t}^{O P T *}=\left(1-\tau_{t}^{L}\right) w_{t} L_{t}^{O P T}+R_{t-1} b_{t-1}^{O P T}-R_{t-1}^{*} s_{t} b_{t-1}^{O P T *} \\
& +\Omega_{T, t}+\Omega_{N, t}+\vartheta^{K} \tau^{K}\left(r_{T, t}^{K} k_{T, t-1}+r_{N, t}^{K} k_{N, t-1}\right)+s_{t} r m_{t}^{*}+z_{t}-\mu k_{G, t-1}-\Theta_{t}^{O P T *}
\end{aligned}
$$

$\beta$ is the discount factor. $\sigma$ and $\psi$ are the inverse of the inter-temporal elasticity of substitution of consumption and of labor supply. $\kappa^{O P T}$ is the disutility weight of labor. $\tau_{t}^{C}$ and $\tau_{t}^{L}$ are the effective tax rates on consumption and labor income. $b_{t}^{O P T}$ is domestic government bonds that pay $R_{t} b_{t}^{O P T}$ units of the consumption basket at time $t+1, b_{t}^{O P T *}$ is liabilities to the rest of the world that entail repayment of $R_{t}^{*} b_{t}^{O P T *}$ units of the foreign consumption basket. $\Omega_{T, t}$ and $\Omega_{N, t}$ are firms' profits in the traded and nontraded good sector. The term $\vartheta^{K} \tau^{K}\left(r_{T, t}^{K} k_{T, t-1}+\right.$ $\left.r_{N, t}^{K} k_{N, t-1}\right)$ is a tax rebate that optimizing households receive on the tax levied on the firms' return on capital. ${ }^{1} r m_{t}^{*}$ is remittance from abroad, $z_{t}$ are government transfers. $\mu$ is user fees of public capital $k_{G, t}$, and $\Theta_{t}^{O P T *} \equiv \frac{\eta}{2}\left(b_{t}^{O P T *}-b^{O P T *}\right)^{2}$ are portfolio adjustment costs associated to foreign liabilities, where $\eta$ controls the degree of capital account openness and $b^{O P T *}$ (a variable without a time subscript) is the initial the steady-state value.

We assume that the private sector pays a constant premium $u$ over the interest rate that the government pays on external commercial debt $R_{d c, t}$, such that

$$
R_{t}^{*}=R_{d c, t}+u \text {. }
$$

A.2. Hand-to-mouth households. Hand-to-mouth households have the same utility function as optimizing households

$$
U\left(c_{t}^{H T M}, L_{t}^{H T M}\right)=\frac{1}{1-\sigma}\left(c_{t}^{H T M}\right)^{1-\sigma}-\frac{\kappa^{H T M}}{1+\psi}\left(L_{t}^{H T M}\right)^{1+\psi} .
$$

Their consumption is determined by the budget constraint

$$
\left(1+\tau_{t}^{C}\right) c_{t}^{H T M}=\left(1-\tau_{t}^{L}\right) w_{t} L_{t}^{H T M}+s_{t} r m_{t}^{*}+z_{t}-\mu k_{G, t-1} .
$$

Static maximization of the utility function gives the labor supply function:

$$
L_{t}^{H T M}=\left[\frac{1}{\kappa^{H T M}} \frac{1-\tau_{t}^{L}}{1+\tau_{t}^{C}}\left(c_{t}^{H T M}\right)^{-\sigma} w_{t}\right]^{\frac{1}{\psi}} .
$$

A.3. Aggregation. With two types of households, aggregate consumption, labor, privately owned government bonds, and foreign liabilities are computed as follows.

$$
\begin{gathered}
c_{t}=\omega c_{t}^{O P T}+(1-\omega) c_{t}^{H T M}, \\
L_{t}=\omega L_{t}^{O P T}+(1-\omega) L_{t}^{H T M}
\end{gathered}
$$

\footnotetext{
${ }^{1}$ Because of the common wedge between tax burden imposed and tax revenues accrued to the government in developing countries, we assume that a fraction $\vartheta^{K}$ of the tax revenue related to capital income does not enter the government budget constraint.
} 


$$
b_{t}=\omega b_{t}^{O P T} ; \quad b_{t}^{*}=\omega b_{t}^{O P T *}
$$

\section{B. Firms}

The economy has three production sectors: (i) a nontraded good sector indexed by $N$; (ii) a (non-resource) traded good sector indexed by $T$; and a natural resource sector indexed by $O$. Since resource rich developing countries tend to export most resource output, we assume that the whole resource output is exported for simplicity.

B.1. Nontraded good sector. Nontraded good firms produce output $y_{N, t}$ with technology

$$
y_{N, t}=z_{N}\left(k_{N, t-1}\right)^{1-\alpha_{N}}\left(L_{N, t}\right)^{\alpha_{N}}\left(k_{G, t-1}\right)^{\alpha_{G}}
$$

where $z_{N}$ is total factor productivity, $k_{N, t}$ is end-of-period private capital, $k_{G, t}$ is the end of period public capital, $\alpha_{N}$ is the labor share of sectoral income, and $\alpha_{G}$ is the output elasticity respect to public capital.

Capital installed in the nontraded good sector evolves by

$$
k_{N, t}=\left(1-\delta_{N}\right) k_{N, t-1}+\left[1-\frac{\kappa_{N}}{2}\left(\frac{i_{N, t}}{i_{N, t-1}}-1\right)^{2}\right] i_{n, t},
$$

where $i_{N, t}$ represents investment expenditure, $\delta_{N}$ is the capital depreciation rate, and $\kappa_{N}$ is the investment adjustment cost parameter.

The representative nontraded good firm chooses labor $\left(L_{N, t}\right)$, capital $\left(k_{N, t}\right)$, and investment $\left(i_{N, t}\right)$ to maximize its discounted lifetime profits weighted by the marginal utility of consumption of optimizing households $\lambda_{t}$,

$$
\Omega_{T, 0}=E_{0} \sum_{t=0}^{\infty} \beta^{t} \lambda_{t}\left[p_{N, t} y_{N, t}-w_{N, t} L_{N, t}-i_{N, t}-\tau^{K} r_{N, t}^{K} k_{N, t-1}\right],
$$

where $r_{N, t}^{K}=\left(1-\alpha_{N}\right) p_{N, t} \frac{y_{N, t}}{k_{N, t-1}}$ is the return to capital.

B.2. Traded good sector. Analogously to the nontraded good sector, firms in the traded good sector produce with technology

$$
y_{T, t}=z_{T, t}\left(k_{T, t-1}\right)^{1-\alpha_{N}}\left(L_{T, t}\right)^{\alpha_{N}}\left(k_{G, t-1}\right)^{\alpha_{N}} .
$$

To capture the common Dutch disease associated with spending resource revenues, we assume total factor productivity, $z_{T, t}$, is subject to learning-by-doing externalities:

$$
\frac{z_{T, t}}{z_{T}}=\left(\frac{z_{T, t-1}}{z_{T}}\right)^{\rho_{z_{T}}}+\left(\frac{y_{T, t-1}}{y_{T}}\right)^{\rho_{y_{T}}}
$$

where $\rho_{z_{T}}, \rho_{y_{T}} \in[0,1]$ control the severity of Dutch disease. The law of motion of private capital is 


$$
k_{T, t}=\left(1-\delta_{T}\right) k_{T, t-1}+\left[1-\frac{\kappa_{T}}{2}\left(\frac{i_{T, t}}{i_{T, t-1}}-1\right)^{2}\right] i_{T, t} .
$$

Like nontraded good firms, a representative traded good firm chooses labor $\left(L_{T, t}\right)$, capital $\left(k_{T, t}\right)$, and investment $\left(i_{T, t}\right)$ to maximize its discounted lifetime profits,

$$
\Omega_{T, 0}=E_{0} \sum_{t=0}^{\infty} \beta^{t} \lambda_{t}\left[y_{T, t}-w_{T, t} L_{T, t}-i_{T, t}-\tau^{K} r_{T, t}^{K} k_{T, t-1}\right] .
$$

B.3. Natural resource sector. As most natural resource production is capital intensive and much of investment in the resource sector is financed by foreign direct investment in developing countries, natural resource production is simplified in the model.

Resource production follows an exogenous process

$$
\frac{\tilde{y}_{o, t}}{\tilde{y}_{o}}=\left(\frac{\tilde{y}_{o, t-1}}{\tilde{y}_{o}}\right)^{\rho_{y o}} \exp \left(\varepsilon_{t}^{y o}\right)
$$

where $\rho_{y o} \in(0,1)$ is an auto-regressive coefficient and $\varepsilon_{t}^{y o} \sim i i d \mathcal{N}\left(0, \sigma_{y o}^{2}\right)$ is the resource production shock. We assume that resource production is small relative to world production; hence, the international commodity price (relative to the foreign consumption basket), $p_{O, t}^{*}$, is taken as given. It is assumed to evolve following the process:

$$
\frac{p_{O, t}^{*}}{p_{O}^{*}}=\left(\frac{p_{O, t-1}^{*}}{p_{O}^{*}}\right)^{\rho_{y o}} \exp \left(\varepsilon_{t}^{p o}\right)
$$

where $\rho_{p o} \in(0,1]$ is an auto-regressive coefficient and $\varepsilon_{t}^{p o} \sim \operatorname{iid} \mathcal{N}\left(0, \sigma_{\text {po }}^{2}\right)$ is the resource price shock. Resource GDP in units of the domestic consumption basket is

$$
y_{O, t}=s_{t} p_{O, t}^{*} \tilde{y}_{O, t} \text {. }
$$

Let $\tau_{t}^{O}$ be the royalty rate on production. Then, the resource revenue collected each period is

$$
t_{t}^{O}=s_{t} \tau_{t}^{O} p_{O, t}^{*} \tilde{y}_{O, t}
$$

\section{Government}

The government flow budget constraint is

$$
\begin{aligned}
& \tau_{t}^{C} c_{t}+\tau_{t}^{L} w_{t} L_{t}+t_{O, t}+\left(1-\vartheta^{K}\right) \tau^{K}\left(r_{T, t}^{K} k_{T, t-1}+r_{N, t}^{K} k_{N, t-1}\right) \\
& +b_{t}+s_{t} d_{t}+s_{t} d_{c, t}+s_{t} R^{R F} f_{t-1}^{*}+\mu k_{G, t-1} \\
& \quad=p_{t}^{G}\left(g_{t}^{c}+g_{t}^{I}\right)+z_{t}-s_{t} g r_{t}^{*}+R_{t-1} b_{t-1}+s_{t} R_{d c, t-1} d_{c, t-1}+s_{t} f_{t}^{*}
\end{aligned}
$$

where $g r_{t}^{*}$ is international grants. The user fee paid on public capital is computed as a fraction $f$ of recurrent costs: $\mu \equiv f p_{t}^{G} \delta_{G}$. The government has three debt instruments: external concessional debt $\left(d_{t}\right)$, external commercial debt $\left(d_{c, t}\right)$, and domestic debt $\left(b_{t}\right)$. Concessional loans extended by official creditors are taken as exogenous in the model. $R_{d}$ and $R_{d c, t}$ are the gross real interest rates paid on concessional debt and external commercial debt. The latter incorporates a risk premium depending on the deviations of total external public debt to GDP ratio from its initial steady state,

$$
R_{d c, t-1}=R^{f}+v_{d c} \exp \left[\eta_{d c}\left(\frac{d_{t}+d_{c, t}}{y_{t}}-\frac{d+d_{c}}{y}\right)\right],
$$


where $R^{f}$ is a (constant) risk-free world interest rate, $y_{t}$ is total GDP and $v_{d c}$ and $\eta_{d c}$ are structural parameters.

For all fiscal approaches analyzed in Section V, public investment paths (as a share of GDP) are computed outside the model and taken as exogenous. Except for the fiscal approach that increases transfers, all other approaches assume constant transfers as a share of GDP. Throughout all simulations, government consumption is kept constant as the level in a trendgrowth path.

C.1. Government purchases. Government purchases comprise government consumption $\left(g_{t}^{C}\right)$ and public investment $\left(g_{t}^{I}\right)$. Like private consumption, government expenditure, $g_{t} \equiv g_{t}^{C}+$ $g_{t}^{I}$, is also a CES aggregate of domestic traded goods, $g_{T, t}$ and domestic nontraded goods, $g_{N, t}$. Thus,

$$
g_{t}=\left[v_{t}^{\frac{1}{\chi}}\left(g_{N, t}\right)^{\frac{\chi-1}{\chi}}+\left(1-v_{t}\right)^{\frac{1}{\chi}}\left(g_{T, t}\right)^{\frac{\chi-1}{\chi}}\right]^{\frac{\chi}{\chi-1}}
$$

where $v_{t}$ is the weight given to nontraded goods in government purchases. Government purchases have the same intra-temporal elasticity of substitution $\chi>0$ as private consumption. $p_{t}^{G}$ is the government consumption price index in terms of units of the consumption basket,

$$
p_{t}^{G}=\left[v_{t} p_{N}^{1-\chi}+\left(1-v_{t}\right) s_{t}^{1-\chi}\right]^{\frac{1}{1-\chi}}
$$

Note that $v_{t}$ is time-varying. As we focus on the effects of additional government spending in public investment, the weight given to nontraded goods for the additional government spending, $v_{g}$, can differ from its steady state value, $v$.

\section{C.2. Public investment efficiency, absorptive capacity constraints, and public capital} depreciation. Public investment features inefficiency and absorptive capacity constraints. To reflect this, we assume that investment efficiency on additional investment above a threshold level drops from the steady-state efficiency value $\epsilon$ to a lower value $\tilde{\epsilon}$. Let $\tilde{g}_{t}^{I}$ denote the effect public investment, and $s_{t}^{G I} \equiv \frac{g_{t}^{I}}{y_{t}}$ be the public investment-to-output ratio with $y_{t}$ being the real GDP. Then,

$$
\tilde{g}_{t}^{I}=\left\{\begin{array}{ll}
\epsilon g_{t}^{I}, & \text { when } s_{t}^{G I}<\bar{s}^{G I} \\
\epsilon\left(\bar{s}^{G I} y_{t}\right)+\tilde{\epsilon}\left(g_{t}^{I}-\bar{s}^{G I} y_{t}\right), & \text { when } s_{t}^{G I} \geq \bar{s}^{G I}
\end{array}\right\}
$$

where $\bar{S}^{G I}$ is the threshold value that triggers efficiency costs associated with absorptive capacity constraints.

The law of motion of public capital is

$$
k_{G, t}=\left(1-\delta_{G}\right) k_{G, t-1}+\tilde{g}_{t}^{I},
$$

where $\delta_{G}$ is the depreciation rate of public capital.

C.3. Resource fund and fiscal gap. Let $f_{t}^{*}$ be the foreign financial asset value in a resource fund, and it serves as a fiscal buffer to absorb fiscal surplus or deficits. Each period, the 
resource fund earns interest income $s_{t}\left(R^{r f}-1\right) f_{t-1}^{*}$, with a constant gross real interest rate $R^{r f}$. When the resource fund reaches zero, a government has to resort to borrowing to cover the revenue shortfall, which then triggers fiscal adjustments to maintain debt sustainability.

To formalize the function of the resource fund, we assume that the resource fund evolves by the process

$$
f_{t}^{*}-f^{*}=\max \left\{-f^{*},\left(f_{t-1}^{*}-f^{*}\right)+\frac{f_{\text {int }, t}}{s_{t}}-\frac{f_{\text {out }, t}}{s_{t}}\right\}
$$

where $f_{\text {int }, t}$ represents the total fiscal inflow, $f_{\text {out }, t}$ represents the total fiscal outflow. Every period, if the fiscal inflow exceeds the outflow, a resource fund increases its value. ${ }^{2}$ Instead, if the fiscal inflow falls short of the outflow, the fund is drawn down to support government spending. We assume that the resource fund cannot accumulate liabilities. Thus, when $f_{t-1}^{*}+\frac{f_{\text {int }, t}}{s_{t}}-\frac{f_{\text {out }, t}}{s_{t}}<0$ (i.e., the fund does not have sufficient assets to be drawn down to cover the difference between the fiscal inflow and outflow), $f_{t}^{*}$ is set to zero. Later we explicitly define $f_{\text {int }, t}$ and $f_{\text {out }, t}$ and explain in detail the mechanism of closing the fiscal gap.

Given the paths of public investment, concessional borrowing, foreign aids and grants, algebraic manipulation of (25) allows the government budget constraint to be rewritten as

$$
\operatorname{gap}_{t}=f_{\text {out }, t}-f_{\text {int }, t}+s_{t}\left(f_{t}^{*}-f_{t-1}^{*}\right)
$$

where

$$
\begin{gathered}
g a p_{t}=\Delta b_{t}+s_{t} \Delta d_{c, t}+\left(\tau_{t}^{C}-\tau^{C}\right) c_{t}+\left(\tau_{t}^{L}-\tau^{L}\right) w_{t} l_{t}{ }^{3} \\
f_{\text {int }, t}=\tau^{C} c_{t}+\tau^{L} w_{t} L_{t}+\left(1-\vartheta^{K}\right) \tau^{K}\left(r_{T, t}^{K} k_{T, t-1}+r_{N, t}^{K} k_{N, t-1}\right)+t_{O, t}+\mu k_{G, t-1} \\
+s_{t} a_{t}^{*}+s_{t} g r_{t}^{*}+s_{t}\left(R^{R F}-1\right) f_{t-1}^{*}+s_{t} \Delta d_{t} \\
f_{\text {out }, t}=p_{t}^{G} g_{t}^{I}+p_{t}^{G} g_{t}^{C}+z_{t}+\left(s_{t} R_{d}-1\right) d_{t-1}+\left(R_{d c, t-1}-1\right) s_{t} d_{c, t-1}+\left(R_{t-1}-1\right) b_{t-1}
\end{gathered}
$$

Equation (33) says that covering the fiscal gap entails domestic and/or external commercial borrowing or adjustments in various fiscal instruments.

When the government has to borrow, we assume that only external debt can be accessed. Thus, $b_{t}=b \forall t$. Debt sustainability requires that eventually revenues have to increase and/or expenditures have to be cut in order to cover the entire gap. In this analysis, we focus on two fiscal adjustment instruments: the consumption and labor income tax rates. ${ }^{4}$ To calculate debt stabilizing (target) values of the two tax rates, the following equations are used.

$$
\tau_{\text {target }, t}^{C}=\tau^{C}+\lambda_{1} \frac{g a p_{t}}{c_{t}}
$$

\footnotetext{
${ }^{2}$ To guarantee that the resource fund is not an explosive process, we assume that in the very long run, a small autoregressive coefficient $\rho_{f} \in(0,1)$ is attached to. The model is typically solved at a yearly frequency for a 1000-period horizon. The coefficient $\rho_{f}$ is activated after the first 100 years of simulations.

${ }^{3}$ In addition tax rates, government consumption and transfers can also be used as fiscal adjustment instruments.

${ }^{4}$ The DIGNAR model can also use government consumption and transfers as fiscal adjustment instruments.
} 


$$
\tau_{\text {target }, t}^{L}=\tau^{L}+\lambda_{2} \frac{g a p_{t}}{w_{t} L_{t}}
$$

where $\lambda_{1}+\lambda_{2}=1$. Tax rates are then determined according to the following policy rules:

$$
\begin{aligned}
& \tau_{t}^{C}=\min \left\{\tau_{\text {rule }, t}^{C}, \tau_{\text {ceiling }}^{C}\right\}, \\
& \tau_{t}^{L}=\min \left\{\tau_{\text {rule }, t}^{L}, \tau_{\text {ceiling }}^{L}\right\},
\end{aligned}
$$

where $\tau_{\text {ceiling }}^{C}$ and $\tau_{\text {ceiling }}^{L}$ are the maximum level of the tax rates can be implemented. Also,

$$
\begin{array}{ll}
\tau_{\text {rule }, t}^{C}=\tau_{t-1}^{C}+\zeta_{1}\left(\tau_{\text {target }, t}^{C}-\tau_{t-1}^{C}\right)+\zeta_{2}\left(x_{t-1}-x\right), & \zeta_{1}, \zeta_{2}>0, \\
\tau_{\text {rule }, t}^{L}=\tau_{t-1}^{L}+\zeta_{3}\left(\tau_{\text {target }, t}^{L}-\tau_{t-1}^{L}\right)+\zeta_{4}\left(x_{t-1}-x\right), & \zeta_{3}, \zeta_{4}>0,
\end{array}
$$

where $\zeta$ 's control the speed of fiscal adjustments, and $x_{t} \equiv \frac{b_{t}+s_{t} d_{c, t}}{y_{t}}$ is the sum of domestic and external commercial debt as a share of GDP.

\section{Identities and Market Clearing Conditions}

To close the model, the goods market clearing condition and the balance of payment conditions are imposed. The market clearing condition for nontraded goods is

$$
y_{N, t}=\varphi p_{N, t}^{-x}\left(c_{t}+i_{N, t}+i_{T, t}\right)+v_{t}\left(\frac{p_{N, t}}{p_{t}^{G}}\right)^{-x} g_{t}
$$

The balance of payment condition is

$$
\frac{c a_{t}^{d}}{s_{t}}=g r_{t}^{*}-\Delta f_{t}^{*}+\Delta d_{t}+\Delta d_{c, t}+\Delta b_{t}^{*}-\Omega_{t}^{O *},
$$

where $\Omega_{t}^{O *}=\frac{y_{O, t}-t_{O, t}}{s_{t}}$ is the dividend from resource production, ${ }^{5}$ and $c a_{t}^{d}$ is the current account deficit:

$$
\begin{aligned}
c a_{t}^{d}=c_{t} & +i_{N, t}+i_{T, t}+p_{t}^{G} g_{t}+\Theta_{t}^{O P T *}-y_{t}-s_{t} r m_{t}^{*}+\left(R_{d}-1\right) s_{t} d_{t-1} \\
& +\left(R_{d c, t-1}-1\right) s_{t} d_{c, t-1}+\left(R_{t-1}^{*}-1\right) s_{t} b_{t-1}^{*}-\left(R^{R F}-1\right) s_{t} f_{t-1}^{*}
\end{aligned}
$$

Finally, total real GDP, $y_{t}$ is given by

$$
y_{t}=p_{N, t} y_{N, t}+s_{t} y_{T, t}+y_{O, t} \text {. }
$$

\section{E. Model Equilibrium, Solution, and Calibration}

The equilibrium system of the model consists of first-order conditions for all optimization problems of the households and firms, market clearing conditions, the balance of payment condition, and exogenous paths of resource variables (resource production quantities, prices, and revenues as a share of GDP), public investment and transfers to households, and concessional debt. We solve for a perfect foresight solution, using dynare's nonlinear solver.

\footnotetext{
${ }^{5}$ For simplicity, we assume there is no cost in resource production, and the dividends are received by foreigners.
} 
The initial steady state is calibrated to the recent conditions of each country, based national accounts and fiscal data. For countries with multiple resource commodities, the resource output quantity and prices shocks, $\left\{\varepsilon_{t}^{y o}\right\}$ and $\left\{\varepsilon_{t}^{p o}\right\}$, are calibrated to the major commodity of a country. Resource revenues paths used in simulations, however, include all resource commodities, and the resource tax rates are endogenously determined to target a particular path.

When calibrating the model to the four countries, the national account aspects of the model are calibrated to recent economic conditions of each country. Most structural parameters, however, are calibrated to those used in Melina et al. (2014) due to lack of country-specific data or estimates. We discuss here a few important parameters and main deviations from their calibration. First, the output elasticity with respect to public capital, $\alpha_{G}$, are chosen such that each country has an annual net rate of return to public capital at 20 percent. ${ }^{6}$ Second, public investment efficiency is set to 0.5, following Pritchett's (2000) estimates for SSA countries. We further assume that investment efficiency can drop to 0.35 for the additional investment that exceeds a threshold level, setting at 60 percent of initial investment as a share of GDP. ${ }^{7}$ Third, to calibrate the share of households that are forward-looking, having access to financial and capital market, we resort to Financial Access data: Households that have a bank account in a formal financial institution is about 25 percent (Ardic et al., 2013). Thus, we set $\omega=0.25$, implying that 75 percent of households are hand-to-mouth. For rationales in calibration other parameters, please Melina et al. (2014). Table 1 lists the calibrated values of the key structural parameters.

\footnotetext{
${ }^{6}$ This assumption may be somewhat conservative. The median return of the World Bank projects is 24 percent in 2008 (International Bank of Reconstruction and Development and the World Bank, 2010).

${ }^{7}$ There is little empirical evidence in quantifying the efficiency costs associated with absorptive capacity constraints. Arestoff and Hurlin (2006) estimate the investment efficiency for Mexico, and find that investment efficiency drops to a lower level when investment expenditures are 60 percent above the sample average.
} 


\begin{tabular}{|c|c|c|}
\hline \multicolumn{3}{|c|}{ Appendix 3. Table 1. Calibration of Key Structural Parameters Across the Four Countries } \\
\hline Parameter & values & notes \\
\hline$\omega$ : share of optimizing households & 0.25 & $\begin{array}{l}\text { implying } 75 \% \text { of households are } \\
\text { hand-to-mouth }\end{array}$ \\
\hline$\sigma$ : inverse of intertemporal substitution elasticity & 2.94 & Ogaki et al. (1996) \\
\hline$\psi:$ inverse of Frisch labor elasticity & 10 & minimizing income effect in labor \\
\hline$\chi$ : substitution elasticity, traded \& nontraded goods & 0.44 & Stockman and Tesar (1995) \\
\hline$\rho$ : substitution elasticity between $L_{N, t}$ and $L_{T, t}$ & 1 & Horvath $(2000)$ \\
\hline$\alpha_{N}$ : labor income share in nontraded good sector & 0.45 & Buffie et al. (2012) \\
\hline$\alpha_{\mathrm{T}}:$ labor income share in traded good sector & 0.6 & Buffie et al. (2012) \\
\hline$\alpha_{G}$ : output elasticity with respect to public capital & $.05-.14$ & $\begin{array}{l}\text { Chosen to target the annual net } \\
\text { return to public capital is } 20 \%\end{array}$ \\
\hline$\kappa_{N}, \kappa_{T}$ : investment adjustment cost & 25 & Beg et al. (2010) \\
\hline$\delta_{G}:$ annual depreciation rate of public capital & 0.07 & Melina et al. (2014) \\
\hline$\delta_{N}, \delta_{T}$ : annual depreciation rate of private capital & 0.10 & Melina et al. (2014) \\
\hline$\rho_{Z T}, \rho_{Y T}:$ learning-by-doing parameter & 0.1 & Berg et al. (2010), mild externality \\
\hline$\epsilon:$ steady-state efficiency of public investment & 0.5 & Pritchett (2000) for SSA countries \\
\hline $\begin{array}{l}\bar{\epsilon} \text { : lower efficiency on additional investment when } \\
\text { absorptive capacity is constrained }\end{array}$ & 0.35 & Arestoff and Hurlin (2006) \\
\hline$R^{R F}-1$ : net real rate earned by resource fund & $2.7 \%$ & Gros and Mayer (2010) \\
\hline$R_{d c}-1$ : net real rate on external commercial debt & $6 \%$ & Buffie et al. (2012) \\
\hline
\end{tabular}


Appendix 3. Figure 1. Simulation Results: Côte d'Ivoire, Baseline and Optimistic Scenarios
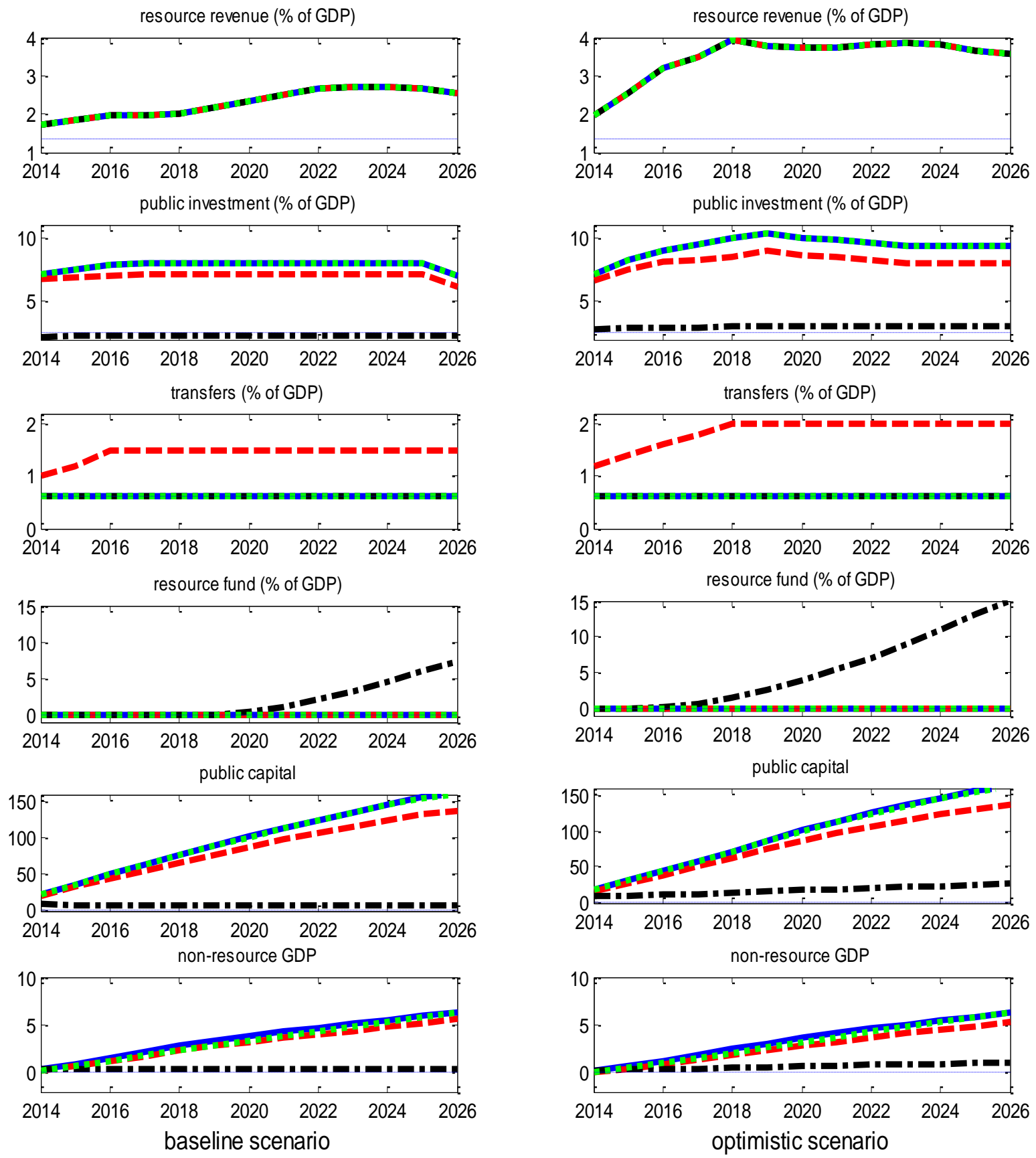

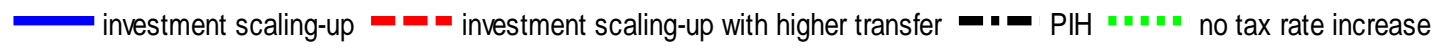

Note: The units of $y$-axis are in perfect deviation from a trend growth path, unless specified in parentheses. 
Appendix 3. Figure 1. Simulation Results: Cote d'Ivorie, Baseline and Optimistic Scenarios (concluded)
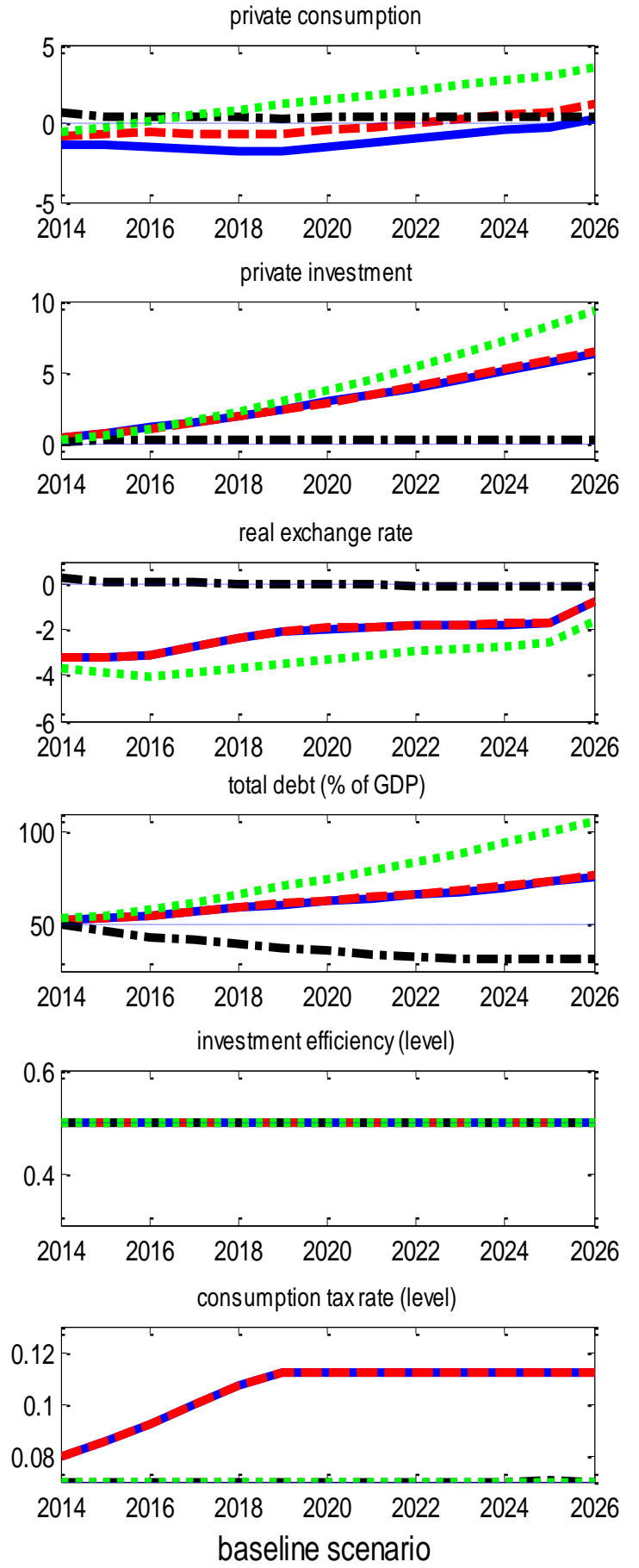
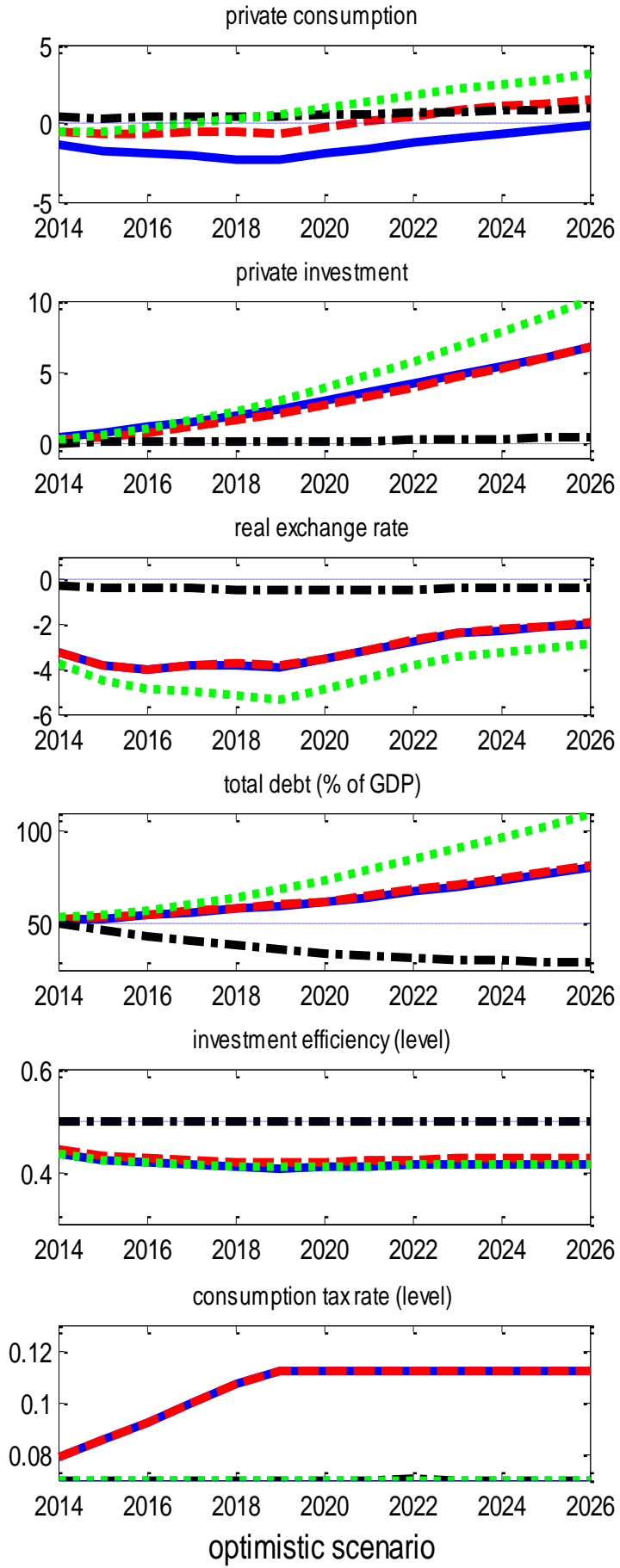

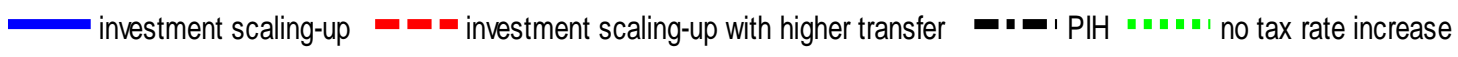

Note: The units of $y$-axis are in perfect deviation from a trend growth path, unless specified in parentheses. 


\section{Appendix 3. Figure 2. Simulation Results: Guinea, Baseline and Optimistic Scenarios}
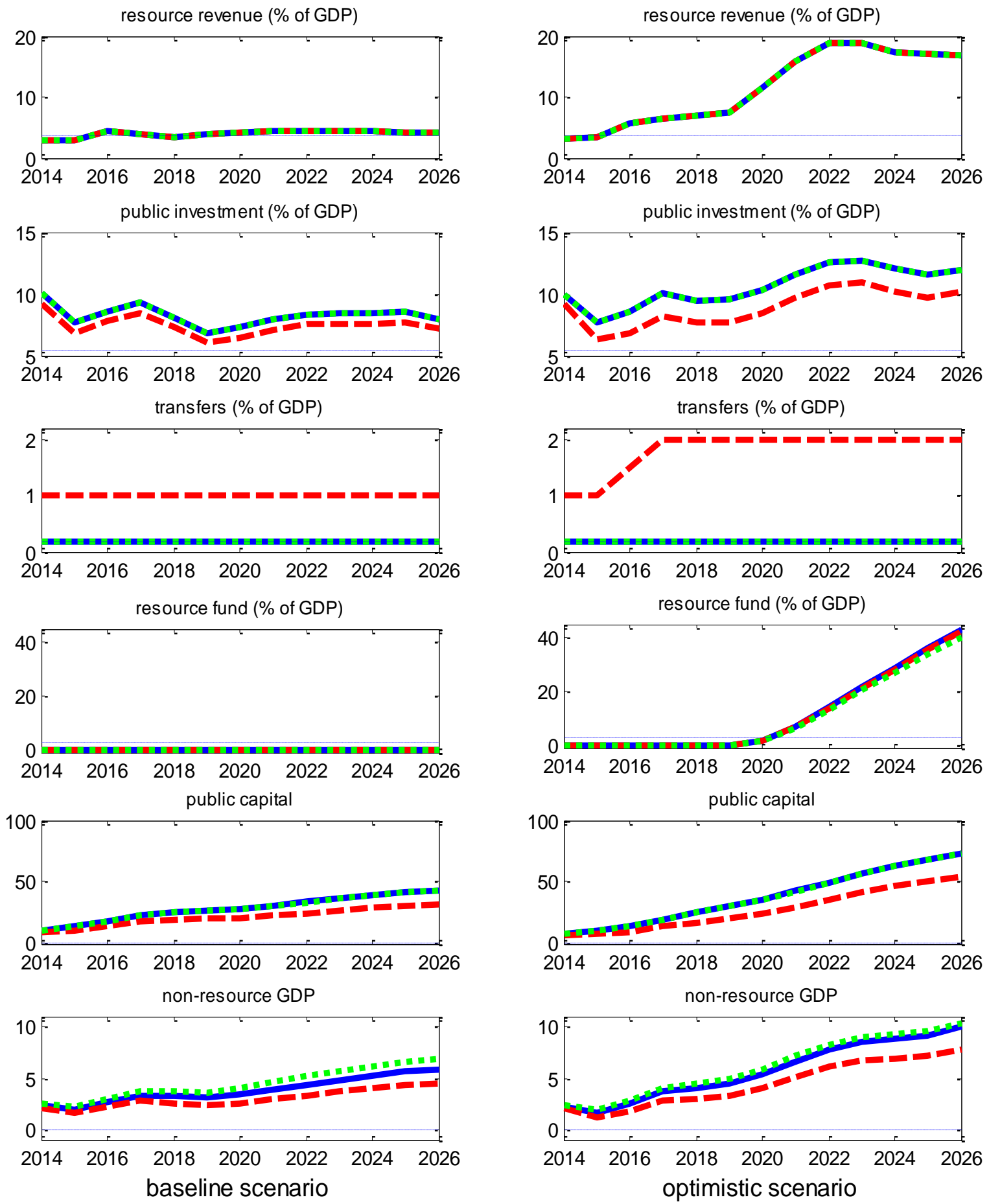

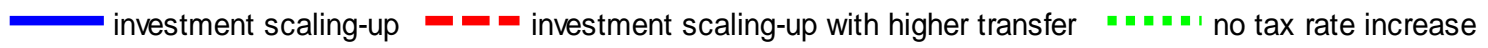

Note: The units of $y$-axis are in perfect deviation from a trend growth path, unless specified in parentheses. 


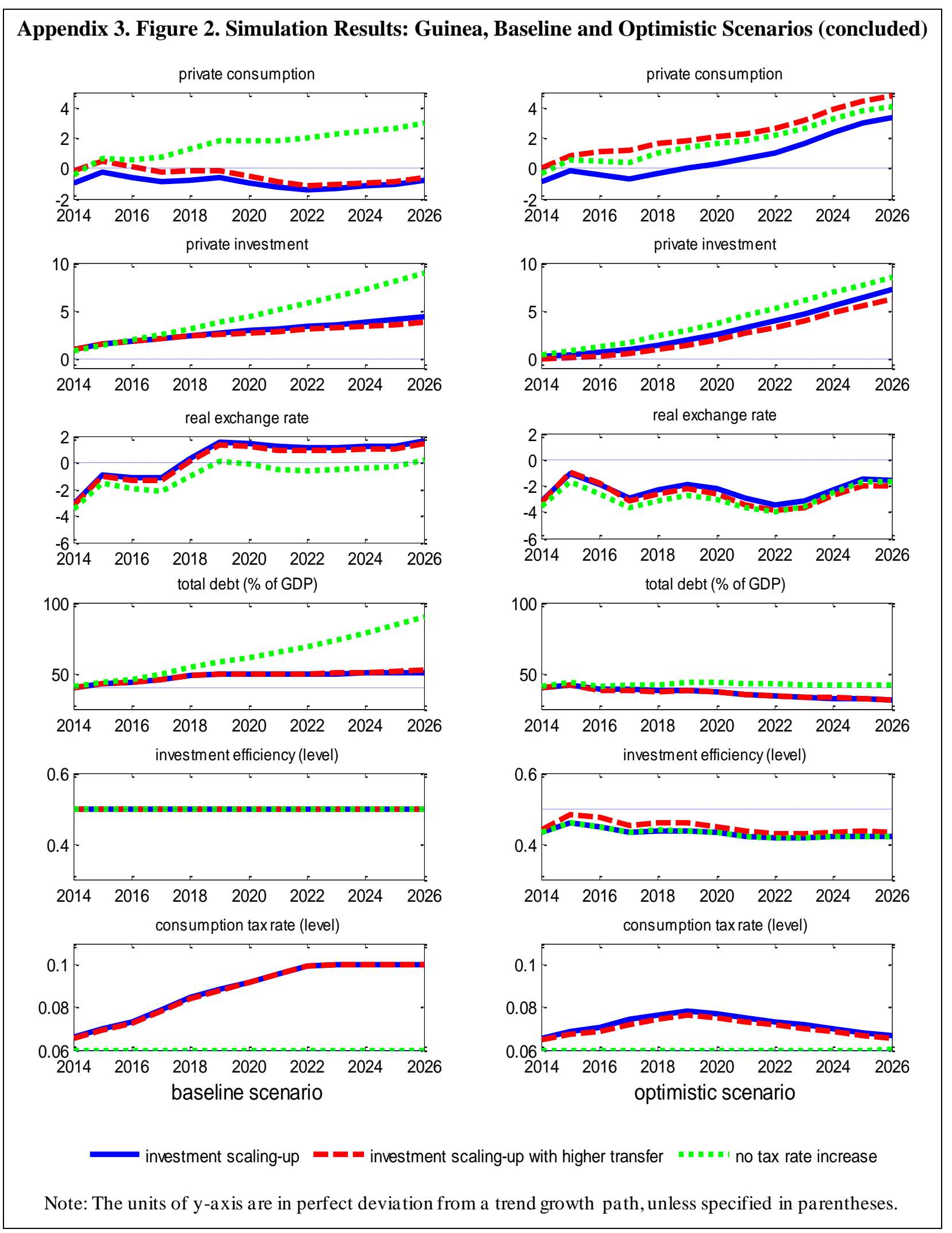


Appendix 3. Figure 3. Simulation Results: Sierra Leone, Baseline and Optimistic Scenarios
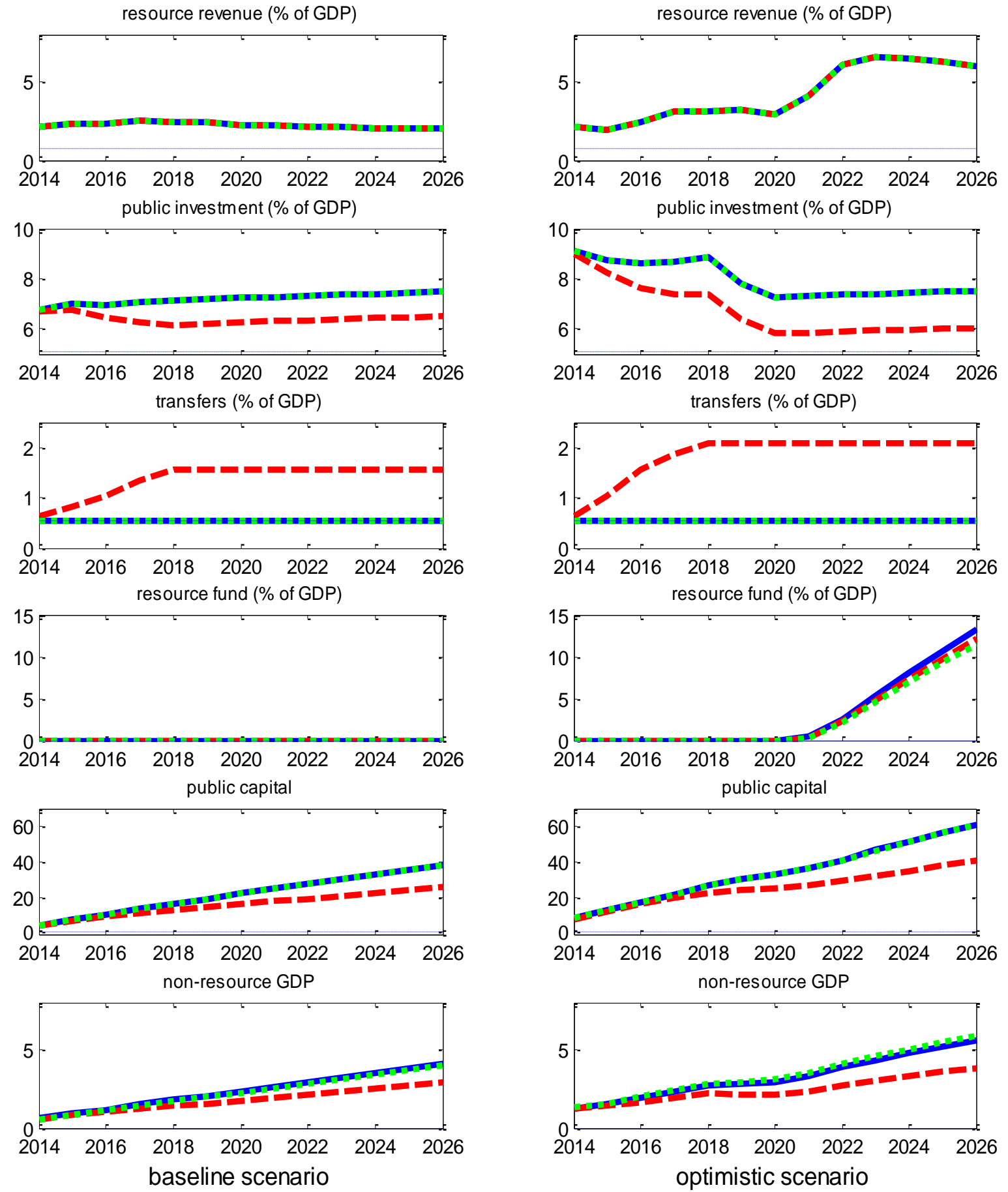

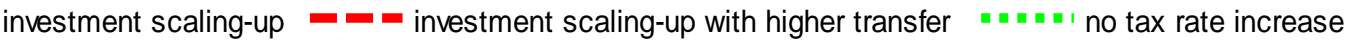

Note: The units of $\mathrm{y}$-axis are in perfect deviation from a trend growth path, unless specified in parentheses. 
Appendix 3. Figure 3. Simulation Results: Sierra Leone, Baseline and Optimistic Scenarios (concluded)
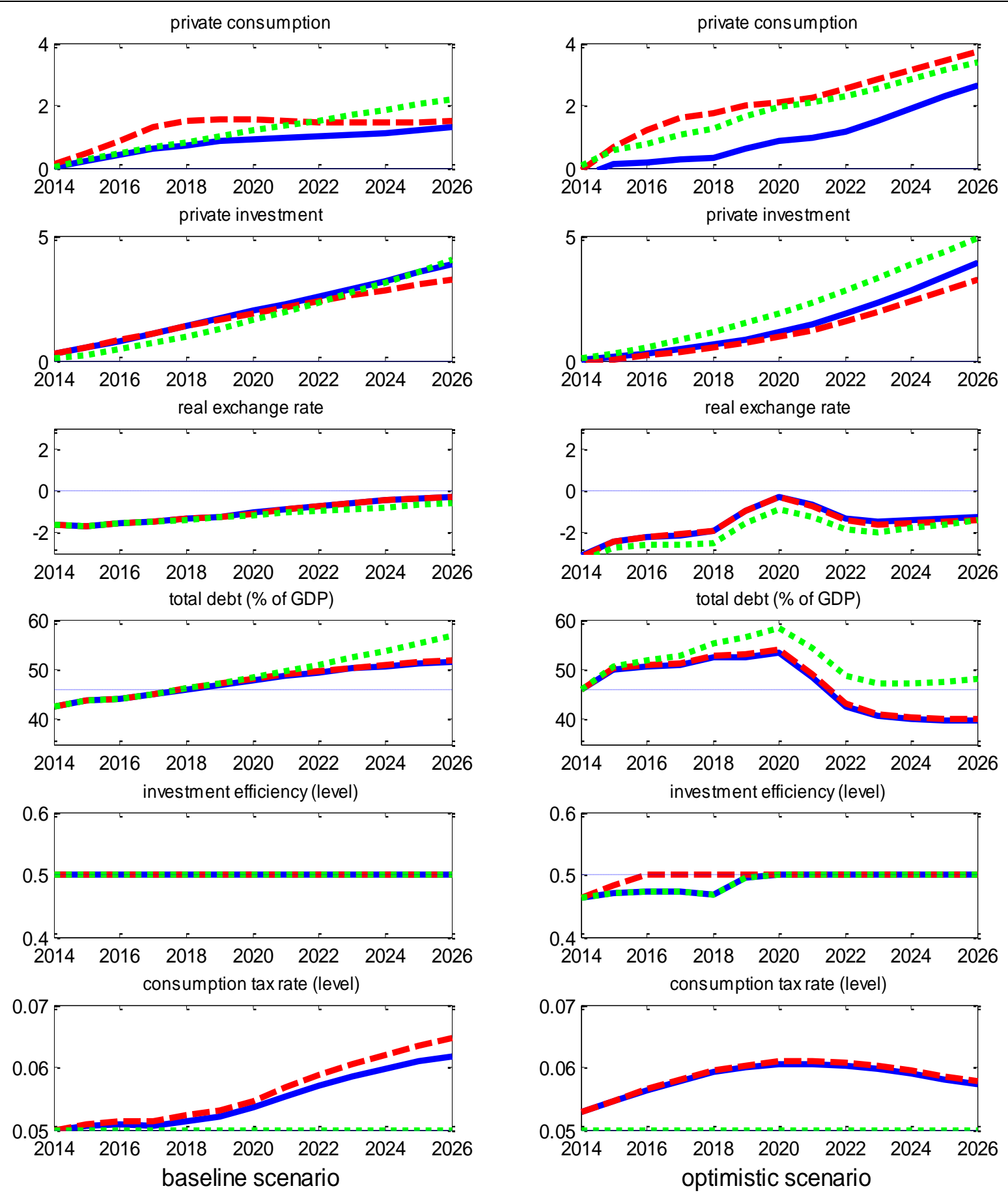

investment scaling-up - investment scaling-up with higher transfer $-m=$ no tax rate increase

Note: The units of $y$-axis are in perfect deviation from a trend growth path, unless specified in parentheses. 